Article

\title{
Study of Heat Transfer and the Hydrodynamic Performance of Gas-Solid Heat Transfer in a Vertical Sinter Cooling Bed Using the CFD-Taguchi-Grey Relational Analysis Method
}

\author{
Junpeng Fu * and Jiuju Cai \\ Department of Thermal Engineering, SEP Key Laboratory of Eco-Industry, School of Metallurgy, \\ Northeastern University, Shenyang 110819, China; rcjj@mail.neu.edu.cn \\ * Correspondence: 1210277@stu.neu.edu.cn
}

Received: 4 April 2020; Accepted: 24 April 2020; Published: 2 May 2020

check for updates

\begin{abstract}
The vertical sinter cooling bed (VSCB) is a high-efficiency energy-saving and environmentally friendly waste heat recovery equipment. In this study, a computational fluid dynamics (CFD) convection model was established to reveal the typical factors on the thermodynamic performance in VSCB. Indeed, a multiple performance optimal algorithm based on the Taguchi-grey relational analysis (GRA) method was first applied to investigate the effects of geometric and operational factors, including the diameter of the bed, height of the bed, air mass flow rate, air inlet temperature, and sinter mass flow rate, on improving the heat transfer $(E x)$ and hydrodynamic performance $\left(P_{\text {drop }}\right)$ and obtain the optimum combination of each factor in VSCB. The results found that the diameter of the bed was the most influential factor contributing the multiple types of performance with a contribution rate of $70.51 \%$, followed by the air mass flow rate $(15.84 \%)$, while the height of the bed $(0.27 \%)$ exerted a limited effect on the performance of multiple processes. The optimal combination of factors $\left(\mathrm{A}_{1} \mathrm{~B}_{5} \mathrm{C}_{5} \mathrm{D}_{5} \mathrm{E}_{1}\right)$ was compared with the initially selected parameters by performing a confirmation test. The performances of heat transfer and hydrodynamics were improved by the Taguchi with the GRA method.
\end{abstract}

Keywords: vertical bed; computational fluid dynamic; grey relational analysis; Taguchi method

\section{Introduction}

The vertical cooling bed is widely used in various industries, such as the metallurgical [1], energy [2], chemical [3], and food [4] sectors. In particular, the steel industry accounts for $23.5 \%$ of the energy consumption by the entire industrial sector, which is deemed a process with extensive energy consumption and emission production [5]. Several types of vertical cooling packed beds have been employed in different processes during steel production, such as a slag furnace, vertical pellet furnace, coke dry quench, and sinter vertical packed bed. According to the published literature [6], the energy consumed by the sintering process accounts for $15 \%$ of the total energy consumption of the steel industry. Therefore, studies designed to improve the efficient utilization and recovery of waste heat resources from the sintering process are very important. Furthermore, researchers have focused on developing several methods to reduce energy consumption and increase the efficiency of utilization of available recovered energy waste [6-8]. In general, the circular and linear moving sinter cooling beds use gas leakage with low efficiency. The novelty vertical sinter cooling packed bed was invented for the efficient recovery and utilization of waste heat from the sinter cooling process. Although previous studies have focused on the design parameters, the most effective factor and the contribution rate of the factor to the thermodynamic characteristics have not been investigated using a systematic 
statistical method. In this study, the investigation of the heat transfer performance of vertical sinter cooling bed was the objective function, and the effects of five design factors were investigated with the help of a three-dimensional computational fluid dynamics (CFD)-simulated model. In addition, The Taguchi-grey relational analysis method was used to determine the optimum combination of design factors, simultaneously impacting multiple target functions. Therefore, the aim of this study was to determine the optimal combination of multiple performance characteristics for simultaneously increasing the exergy of the air outlet and reducing the pressure drop in the vertical bed.

\subsection{Vertical Sinter Cooling Bed (VSCB)}

This technical innovation creates a variation in the heat transfer mechanism that transfers cross-flow heat transmission in a circular cooler to counter contact current heat transfer in the VSCB. As shown in Figure 1, the sinter cooling process is operating in the cooling section, where heat transfer is initiated between hot sinter particles and ambient temperature air with direct counter-current contact modes. The blazing sinter block is initially filled in the pre-store chamber that guarantees continuous sinter granular charging and then packed into the cooling section; the air is simultaneously introduced from the center and circular channels and flows through center air cowl into the cooling section. The cooled sinter granule is unloaded using a discharge device at the bottom of the vertical bed and heated air flows through a ramp channel and is recovered at the outlet of the VSCB. The discharge device is composed of an electromagnetic vibrator and rotary sealing valve, ensuring the continuous and smooth discharge of sinter granules at a constant mass flow rate. As described above, the heat transfer process between sinter granular and air occurs in a confined space (cooling section), which contributes to improving the heat transfer efficiency and reducing air leakage.

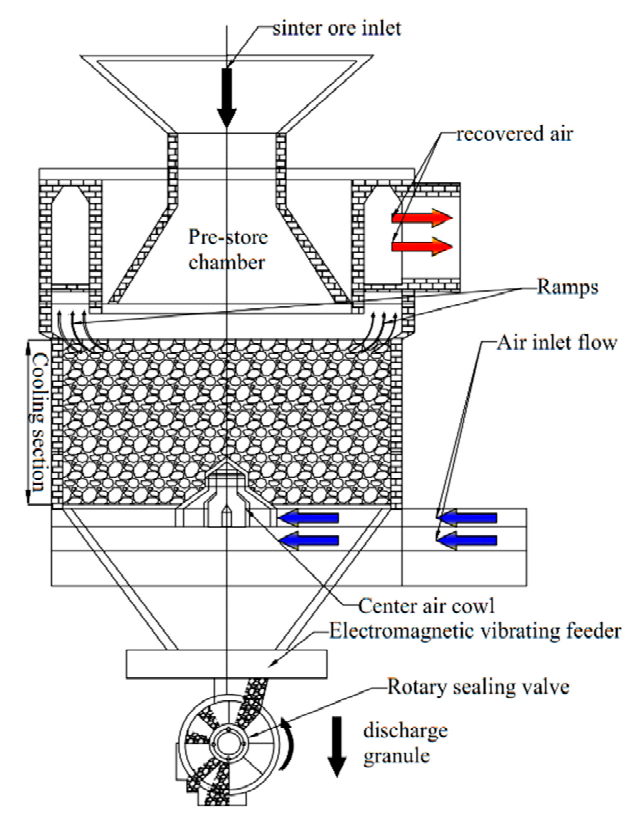

Figure 1. Schematic showing the operation of a vertical sinter cooling bed.

\subsection{Studies of the Heat Transfer Performance of the VSCB}

In the past decade, many investigations aiming to improve heat transfer performance in terms of the exergy and energy have been performed. In general, theoretical, experimental, and simulated methods have been applied to improve the heat transfer performance of the VSCB. The published studies have mainly examined the effect of geometric and operating parameters on the heat transfer process in the VSCB. Feng et al. [9] presented the effects of the air inlet temperature and mass flow rate on the recovered exergy performance based on a three-dimensional simulated model. Zheng et al. $[10,11]$ presented the effects of several design parameters on the volumetric exergy transfer coefficient and 
volumetric transfer coefficient in terms of the second law of thermodynamics and pilot experimental method. Pan et al. [12] established a theoretical model of gas-solid heat exchange to determine the effects of the operational parameters on the heat transfer and pressure drop. Feng et al. [13] determined the overall heat transfer coefficient using a pilot experimental method. In addition, experimental research has been conducted, and the reliability of the Nusselt number has been obtained from regression analysis and verification. Zhang et al. [14] investigated the effects of structural and operating parameters on the exergy performance of waste heat recovery using a 3D calculated model. Four main parameters were studied in terms of exergy and energy consumption. Feng et al. [15] described the sinter bed system used to obtain the optimal combination of design parameters with the help of an orthogonal experiment to improve the heat transfer performance based on a 3D porous medium and non-equilibrium heat exchange model. Pan et al. [16] studied the volumetric heat transfer coefficient and air pressure drop of a sinter layer based on the experimental method. The research on the vertical sinter cooling bed also examined the hydrodynamic performance, such as the pressure drop and energy loss, which are deemed as functions with a negative effect on the effectiveness of the heat resource recovery process. Feng et al. [17] investigated the airflow pattern and pressure drop characteristics using an experimental approach. The flow regimes in the sinter bed were also partitioned into several parts in terms of the critical Reynolds number. The relationship between the pressure drop and the parameters of interest were established simultaneously. Tian et al. [18] studied the air pressure drop through a random distribution sinter packed bed by varying the irregular particle sizes, the porosity of the sinter layer, and sphericity for different flow regimes.

The aforementioned studies, examining the heat transfer performance in a vertical sinter cooling bed, have mainly determined the effects of structural and operational parameters on the energy and exergy performance, which is beneficial for providing comprehensive insights into the heat transfer characteristics in a vertical sinter bed. However, few studies have employed a systematic analytical approach with a statistical analysis of factors of interest that affect the heat transfer performance of the vertical sinter cooling bed along with a simultaneous assessment of multiple purpose functions. To our knowledge, the Taguchi with grey relational analysis (GRA) was established to analyze the effective parameters that affect multiple purpose functions and is necessary to obtain the relationship of the simulated and ideal results in the different design combinations.

\subsection{Studies of the Statistical Analysis Method}

The Taguchi grey relational analysis is a versatile technique that has been applied in various fields, such as iron and steel [19,20], heat exchanger [21], energy systems [22], refrigeration [23], powder metallurgy [24], building material [25], and chemical mechanical planarization [26]. In the present study, the main focus was the application of the Taguchi grey relational analysis method to determine the effects of the design parameters on the heat transfer recovery process. In the literature, many researchers have paid their attention to this topic. N. Celik et al. [27] simultaneously examined the effects of design parameters on the performance of a tabulated heat exchanger and the effects of the optimum design parameters on heat and pressure loss. Kumbhar et al. [28] used the CFD method to investigate the performance of a simple tube with twisted tapes. The twisted tape pitch and dimple pitch are the most important parameters of the system, and the best parameter combination in terms of the performance of heat transfer and friction was identified using the Taguchi-grey relational analysis. Acir et al. [29] investigated the optimal parameter, impacting a novel solar air heater system for efficient energy and exergy transfer using the Taguchi grey relational analysis method. Kuo et al. [30] determined the effects of selected factors on the performance of a flat-plate collector. The optimum operating factors for this system were determined using the Taguchi grey relational analysis. Gunes et al. [31] determined the effects of four optimal design parameters on the two response functions (heat transfer and pressure drop) using the Taguchi grey relational analysis. 
The factors and selected range of the vertical sinter bed used in previous studies are listed in Table 1. The related factors and levels are presented in Table 1 as a reference for selecting the factors of interest.

Table 1. Parameters of interest for the heat transfer process in published studies.

\begin{tabular}{|c|c|c|c|c|c|c|}
\hline \multirow{2}{*}{ Researchers } & \multirow[t]{2}{*}{ Target Functions } & \multicolumn{5}{|c|}{ Parameters } \\
\hline & & $T_{\mathrm{g}, \text { in }}{ }^{1}\left({ }^{\circ} \mathrm{C}\right)$ & $H_{\mathrm{b}}{ }^{2}(\mathrm{~m})$ & $M_{\mathrm{a}}{ }^{3}(\mathrm{~kg} / \mathrm{s})$ & $D_{\mathrm{b}}^{4}(\mathrm{~m})$ & $M_{\mathrm{s}}{ }^{5}(\mathrm{~kg} / \mathrm{s})$ \\
\hline Feng et al. [15] & Exergy performance & $293-373$ & 7 & $170-210$ & 9 & 152 \\
\hline Zhang et al. [14] & $\begin{array}{l}\text { Exergy and energy } \\
\text { consumption }\end{array}$ & 293 & 2 & $60-100$ & $6-10$ & $85-100$ \\
\hline Pan et al. [12] & $\begin{array}{l}\text { Heat transfer and } \\
\text { pressure drop }\end{array}$ & $293-473$ & $2-5$ & - & $8-11$ & 83-139 \\
\hline Feng et al. [15] & $\begin{array}{l}\text { Heat transfer process } \\
\text { analysis }\end{array}$ & 293 & $5-8$ & 170 & $7-10$ & 150-180 \\
\hline Feng et al. [32] & $\begin{array}{c}\text { Energy and exergy } \\
\text { analysis }\end{array}$ & $293-373$ & $5-9$ & $160-200$ & $6-10$ & - \\
\hline
\end{tabular}

${ }^{1}$ represent the air inlet temperature; ${ }^{2}$ represent the height of bed; ${ }^{3}$ mass flow rate of air; ${ }^{4}$ diameter of bed; ${ }^{5}$ mass flow rate of sinter granular.

Based on previous research, the present study mainly focused on the parameters of interest by determining the order of importance of effective factors and contribution rates of factors for simple or multiple target performance in a heat transfer process using a VSCB. The Taguchi grey relational analysis method was introduced to simultaneously improve heat transfer and hydrodynamic performance. First, the CFD convection model was established to determine the variations in heat transfer and hydrodynamic performance characteristics for various factors with different ranges. Then, the Taguchi $\mathrm{L}_{25}\left(5^{5}\right)$ experimental array comprising five concerned factors, with five levels for each factor, was separately applied to investigate the effect of the factor on simple response performance ( $E x$ or $\left.P_{\text {drop }}\right)$ using the Taguchi method. Furthermore, the Taguchi-grey relational analysis method was used to determine the order of effects of the factors of interest on the heat transfer and hydrodynamic performance ( $E x$ and $P_{\text {drop }}$ ) and to simultaneously improve the performance of both responses.

\section{Computational Method and Boundary Condition}

\subsection{Mathematical Description within the CFD}

The airflow through the void space between the sinter ore and sinter particles potentially functions as a sieve, allowing the air to penetrate. The RANS (Reynolds Averaged Navier Stokes) $k-\varepsilon$ turbulence model is used to describe the conservation of air hydrodynamic

Continuity:

$$
\nabla \cdot(\rho \mathbf{u})=0
$$

Momentum equation:

$$
\rho(\mathbf{u} \cdot \nabla) \mathbf{u}=\nabla \cdot\left[-p \mathbf{I}+\left(\mu+\mu_{\mathrm{T}}\right)\left(\nabla \mathbf{u}+(\nabla \mathbf{u})^{\mathrm{T}}\right)-\frac{2}{3}\left(\mu+\mu_{\mathrm{T}}\right)(\nabla \cdot \mathbf{u}) \mathbf{I}-\frac{2}{3} \rho k \mathbf{I}\right]+\mathbf{F}+\mathbf{S}
$$

where $\rho$ is the air density; $\mathbf{u}$ is air the velocity vector; $p$ is the air pressure; $\mathbf{I}$ is the unit direction vector; $\mu$ is the dynamic viscosity; $\mu_{\mathrm{T}}$ is the eddy viscosity, which is defined as a function of the turbulent kinetic energy $(k)$ and turbulent energy dissipation rate $(\varepsilon) ; \mathbf{F}$ is a volumetric force vector; $\mathbf{S}$ is the source term, which includes the viscosity loss and inertial loss term and controlled by the porous media of Navier-Stokes macro-equations. The source term is defined as follows:

$$
\mathbf{S}=-\left(\frac{\mu}{\alpha} \mathbf{u}+\frac{1}{2} C_{2} \rho|\mathbf{u}| \mathbf{u}\right)
$$


where $1 / \alpha$ is coefficient of viscous resistance; $C_{2}$ is the coefficient of inertial resistance, and $\mathbf{u}$ is the air velocity. In this study, the coefficients of viscous and inertial resistance were used to determine the air pressure drop through vertical sinter packed bed based on the modified Ergun correlation [15]. Then, $1 / \alpha$ and $C_{2}$ are calculated as follows:

$$
\begin{aligned}
& \frac{1}{\alpha}=85.4 \frac{(1-\varphi)^{2}}{\varphi^{3}\left(d_{p S M}\right)^{2}} \\
& C_{2}=0.632 \frac{(1-\varphi)}{\varphi^{3}\left(d_{p S M}\right)}
\end{aligned}
$$

where $\varphi$ is the porosity of vertical sinter cooling bed, and $d_{p S M}$ is the Sauter mean diameter (SMD) applied to describe the mean diameter of multi-dispersed sinter particles. The Sauter mean diameter (SMD) is calculated as follows:

$$
d_{p S M}=\frac{1}{\sum \frac{x_{i}}{d_{p, i}}}
$$

where $x_{\mathrm{i}}$ is the size fraction of granular in the size interval $i$. In this study, the average diameter was $0.035 \mathrm{~m}$.

The turbulent transportation equation (RANS $k-\varepsilon$ ) is comprised of turbulent energy transportation and turbulent dissipation transportation equations. The RANS $k-\varepsilon$ model determines the behavior of airflow through the vertical sinter packed bed in the turbulent flow range ( $\operatorname{Re}>300)$, which is calculated as follows:

$$
\left\{\begin{array}{l}
k: \rho(\mathbf{u} \cdot \nabla) k=\nabla \cdot\left[\left(\mu+\frac{\mu_{T}}{\sigma_{k}}\right) \nabla k\right]+P_{k}-\rho \varepsilon \\
\varepsilon: \rho(\mathbf{u} \cdot \nabla) \varepsilon=\nabla \cdot\left[\left(\mu+\frac{\mu_{T}}{\sigma_{\varepsilon}}\right) \nabla \varepsilon\right]+C_{\varepsilon 1} \frac{\varepsilon}{k} P_{k}-C_{\varepsilon 2} \rho \frac{\varepsilon^{2}}{k} \\
\mu_{T}=\rho C_{\mu} \frac{k^{2}}{\varepsilon} \\
P_{k}=\mu_{T}\left[\nabla \mathbf{u}:\left(\nabla u+(\nabla \mathbf{u})^{T}-\frac{2}{3}(\nabla \cdot \mathbf{u})^{2}\right]-\frac{2}{3} \rho k \nabla \cdot \mathbf{u}\right.
\end{array}\right.
$$

where $C \mu=0.09, C \varepsilon 1=1.44$, and $C \varepsilon 2=1.92$ are turbulent constants; and $\sigma_{k}=1.00$ and $\sigma_{\varepsilon}=1.3$ are Prandtl numbers.

The temperature differs between the air and sinter particles in the heat transfer process; thus, in this study, the local thermal non-equilibrium (LTNE) model was applied to describe the behavior of air-sinter heat transfer. The following conservation equations of air and sinter energy are used:

Energy:

Fluid (air):

$$
\rho_{f} \mathcal{C}_{f} \mathbf{u}_{f} \nabla T_{f}=\varepsilon \nabla\left(\lambda_{f} \nabla T_{f}\right)+h_{v}\left(T_{s}-T_{g}\right)
$$

Solid (sinter):

$$
(1-\varepsilon) \rho_{s} \mathcal{c}_{s} \mathbf{u}_{s} \nabla T_{s}=(1-\varepsilon) \nabla\left(\lambda_{s} \nabla T_{s}\right)-h_{v}\left(T_{s}-T_{g}\right)
$$

where $\rho_{f}$ and $\rho_{s}$ are the density of air and sinter, respectively; $c_{f}$ and $c_{s}$ are the specific heat of air and sinter, respectively; $\mathbf{u}_{f}$ and $\mathbf{u}_{s}$ are the velocity of the air and sinter, respectively; $\lambda_{f}$ and $\lambda_{s}$ are the thermal conductivity of air and sinter, respectively; $T_{f}$ and $T_{s}$ are the temperature of air and sinter, respectively; $h_{v}$ is volume coefficient of air-sinter heat transfer that connects air and sinter heat transfer process. The energy source term is added to the last position of the fluid and solid conservation energy equation, which controls the convective heat transfer rate between air and sinter. The Achenbach criterion relation is used to express the volume coefficient of heat transfer $h_{v}$ as follows:

$$
h_{v}=6 h(1-\varepsilon) / d_{p}
$$

where $h$ is the area coefficient of convective heat transfer, according to the results reported by Feng et al. [15], who described air and sinter heat transfer behaviors through a vertical sinter cooling 
packed bed. The modified correlation with the Nusselt number is determined as the coefficient of convective heat transfer $h$ based on the area of heat transfer between air and sinter. The modified correlation, defined as the Nusselt number, is calculated as follows:

$$
N u=\frac{h d_{p}}{\lambda_{g}}=0.198 \varepsilon^{0.07} \operatorname{Re}^{0.66} \operatorname{Pr}^{1 / 3}
$$

where $\mathrm{Re}$ and $\mathrm{Pr}$ are the sinter Reynolds number and air Prandtl number, respectively. $\mathrm{Re}$ and $\mathrm{Pr}$ are calculated as follows:

$$
\begin{gathered}
R e=\frac{\mathbf{u}_{g} \cdot d_{p} \cdot \rho_{g}}{\mu_{g}} \\
\operatorname{Pr}=\frac{c_{g} \cdot \mu_{g}}{\lambda_{g}}
\end{gathered}
$$

In this study, one of the target physical phenomena was the exergy of outlet air, which was significantly affected by the geometry and operating parameters as a response to the variations in several considered factors. Exergy represents the maximum amount of useful work that can be obtained from a vertical sinter packed bed and is deemed as a progressive tool for eliminating energy consumption. Thus, we chose it as a target value in the present study. The exergy of outlet air is calculated as follows:

$$
E_{x}=m\left[E_{x}(T)+E_{x}(p)\right]=m\left\{c_{p}\left(T-T_{0}\right)\left[1-\frac{T_{0}}{T-T_{0}} \ln \frac{T}{T_{0}}\right]+R_{g} T_{0} \ln \frac{p_{0}}{p_{0}+\Delta p}\right\}
$$

where $\mathrm{m}$ is the mass flow rate of air, $\mathrm{kg} \cdot \mathrm{s}^{-1} ; p_{0}$ is the ambient pressure; $\Delta p$ is the pressure drop when air flows through the sinter bed, $\Delta p=p_{\text {inlet }}-p_{\text {outlet }}, p_{\text {inlet }}$, and $p_{\text {outlet }}$ are air pressure at the initial inlet and

\begin{tabular}{|c|c|c|}
\hline Parameters & Unit & Value \\
\hline Air dynamic viscosity [15] & $\mathrm{kg} \cdot \mathrm{m}^{-1} \cdot \mathrm{s}^{-1}$ & $1.711 \times 10^{-5} \times\left(T_{\text {air }} / 273\right)^{1.5} \times(273+122) /\left(T_{\text {air }}+122\right)$ \\
\hline Air density [15] & $\mathrm{kg} \cdot \mathrm{m}^{-3}$ & $1.01325 \times 10^{5} /\left(289 \times T_{\text {air }}\right)$ \\
\hline Air specific heat [15] & $\mathrm{J} \cdot \mathrm{kg}^{-1} \cdot \mathrm{K}^{-1}$ & $\begin{array}{c}103 \times\left(28.11+0.1967 \times 10-2 T_{\text {air }}+0.4802 \times 10-5\right. \\
\left.T_{\text {air }}{ }^{2}+1.996 \times 10-9 T_{\text {air }}{ }^{3}\right) / 28.97\end{array}$ \\
\hline Air conductivity [15] & $\mathrm{W} \cdot \mathrm{m}^{-1} \cdot \mathrm{K}^{-1}$ & $2.72 \times 10^{-4} T_{\text {air }}^{0.8}$ \\
\hline Sinter specific heat [9] & $\mathrm{J} \cdot \mathrm{kg}^{-1} \cdot \mathrm{K}^{-1}$ & $337.03 T_{s}^{0.152}$ \\
\hline Sinter ore density [14] & $\mathrm{kg} \cdot \mathrm{m}^{-3}$ & 2800 \\
\hline
\end{tabular}
final outlet, respectively. $T_{0}$ is the ambient temperature and defined as $298 \mathrm{~K}$. The physical properties of the sinter granular material and air in the calculation are listed in Table 2.

Table 2. Physical parameters of the sinter and gas phases.

Notably, the equation used to calculate the exergy of outlet air is comprised of two terms. The first term on the right is the temperature exergy that provides the impetus for obtaining useful work in the air and sinter heat transfer process. The second term on the right is pressure exergy related to the resistance of the vertical sinter bed. The pressure exergy describes the air pressure drop through the sinter bed related to energy consumption, and its role in eliminating useful work is obtained. In this regard, pressure exergy undermines the heat transfer process between air and sinter. The temperature exergy and pressure exergy are calculated as follows:

$$
E_{x}(T)=c_{p} \int_{T_{0}}^{T} d T-c_{p} T_{0} \int_{T_{0}}^{T} \frac{d T}{T}=c_{p}\left(T-T_{0}\right)\left[1-\frac{T_{0}}{T-T_{0}} \ln \frac{T}{T_{0}}\right]
$$




$$
E_{x}(p)=R_{g} T_{0} \int_{p}^{p_{0}} \frac{d p}{p}=R_{g} T_{0} \ln \frac{p_{0}}{p}=R_{g} T_{0} \ln \frac{p_{0}}{p_{0}+\Delta p}
$$

The various assumptions are presented based on the criteria of a homogenous distribution and statistical analysis to ensure simple and smooth calculations. The cooling section is deemed as the system comprised of a homogenous distribution of sinter granular material and continuous airflow in the heat transfer process. Therefore, several assumptions related to the cooling section for the heat transfer calculation in VSCB are listed below.

1. The sinter granules maintain the mass flow pattern in the cooling section, which is the precondition to ensure steady operation.

2. The sinter granules are deemed a homogenous and isotropic bulk solid material.

3. The heat dissipates at the outer wall of the VSCB is insulated by the insulation material.

\subsection{Determination of the Grid Generation and Boundary Condition}

The ICEM-CFD (Integrated Computer Engineering and Manufacturing code for Computational Fluid Dynamics) tool is usually applied to generate a mesh in a physical model with complex geometry. According to a previous study, the target cooling section is defined as a calculated domain $[14,15,32]$. Smaller calculated workloads, a more rapid convergence process, and more boundary conditions are adopted to obtain a higher mesh quality. Thus, the 3D structured mesh was established to calculate the study target, which was comprised of a quadrilateral and hexahedral grid. The hexahedral grid was applied to generate the fluid domain mesh, and the quadrilateral grid was employed to create the mesh of the faces. The ICEM was applied to create the surface and volume grid and exported to the finite element software ANSYS Fluent 16.0 for calculation. The pressure-velocity coupling method was applied to the SIMPLE algorithm to discretize the control element, and a second upstream scheme was used for pressure and energy spatial discretization. The air and sinter heat transfer cooling system is very complex. Several suitable UDF (user-defined functions) are available that utilize the $C$ programming language to define the parameters, such as the properties of air and sinter, volume heat transmission coefficient $\left(h_{v}\right)$ in energy conservation equations, flux and diffusivity coefficients, and source term $\left(S_{i}\right)$, in user-defined scalar (UDS) transportation equations.

The boundary condition settings are described in Figure 2. The air inlet section is defined as the mass flow inlet boundary condition (the circular flow channel at the bottom of the bed, and center flow channel at the central air cowl) to describe the mass flow rate in compressible airflow. The air outlet section is defined as the pressure outlet boundary condition that defines the outlet with static pressure and is beneficial for better convergence during the simulation in which backflow occurred. The designed specific values for turbulent intensity and hydraulic diameter were used in the specification method. In addition, the relative pressure value at the air outlet was set to zero because the effective pressure drop between the air and wall is not considered for the resistance loss in the computation domain. The other parts of this domain were set as the adiabatic wall condition boundary.

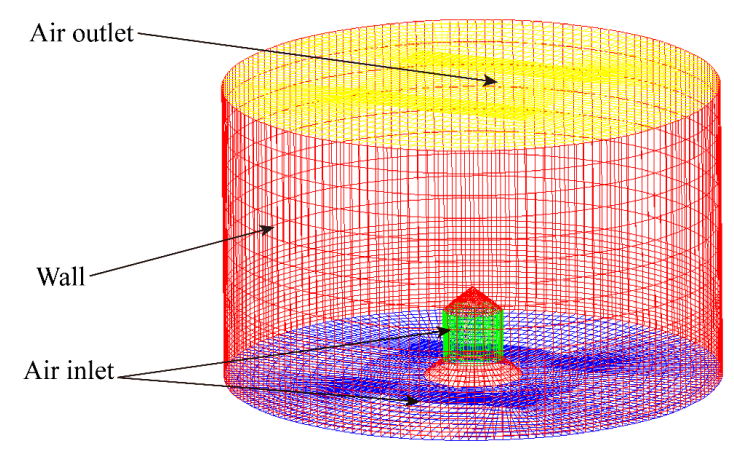

Figure 2. Boundary condition settings and element generation of the simulation domain. 


\subsection{Grid Independence Test and Model Validation}

The computational domain is presented for this study in Figure 2. The function of the mesh independence test was to examine the effect of the number of elements on the simulation data and to obtain the applicable grid for subsequent investigations. The structured grids with quadrilateral elements were employed to display the solid and fluid zones for the non-equilibrium thermal model, where the inlet and outlet boundary conditions were increased for valid computation. The criteria used to judge a high quality of mesh were sufficiently fine to present an accurate and detailed description of flow modes and sufficiently coarse to simulate the process in a suitable time. Therefore, five mesh elements ranging from 19,232 to 399,722 were employed to simulate the heat transfer process. The simulated results are described in Table 3 , which presented a gradual decrease in the deviation of previous and subsequent mesh elements overall. The air and sinter outlet temperatures and pressure drop were set as target functions to determine the reliable mesh element. As shown in Table 3, the relative deviation of the results between case 4 and case 5 was $-0.003,-0.018$, and -0.001 , respectively. As described above, the case $4(172,872)$ was the suitable mesh element used in subsequent calculations.

Table 3. Independent mesh test.

\begin{tabular}{cccccccc}
\hline Case & $\begin{array}{c}\text { Mesh } \\
\text { Element }\end{array}$ & $\begin{array}{c}\text { Air Outlet } \\
\text { Temperature } \\
\mathbf{( K )}\end{array}$ & $\begin{array}{c}\text { Error } \\
\mathbf{( \% )}\end{array}$ & $\begin{array}{c}\text { Sinter Outlet } \\
\text { Temperature } \\
\mathbf{( K )}\end{array}$ & Error (\%) & $\begin{array}{c}\text { Pressure } \\
\text { Drop (Pa) }\end{array}$ & Error (\%) \\
\hline 1 & 19,232 & 758.60 & - & 339.70 & - & 9763.12 & - \\
2 & 42,938 & 758.74 & 0.020 & 339.72 & 0.006 & 9756.59 & -0.067 \\
3 & 91,242 & 758.60 & -0.020 & 339.58 & -0.041 & 9751.69 & -0.050 \\
4 & 172,872 & 758.58 & -0.003 & 339.58 & 0 & 9751.74 & 0 \\
5 & 399,722 & 758.56 & -0.003 & 339.52 & -0.018 & 9750.80 & -0.001 \\
\hline
\end{tabular}

A vertical sinter cooling device that includes heat transfer and pressure drop characteristics was established in this study to verify the reliability of the results from the simulation. The dimensions and components of the experimental device are presented in Figure 3. The calculated diameter and height of the sinter cooling bed were $0.6 \mathrm{~m}$ and $1.6 \mathrm{~m}$, respectively. A U-tube water manometer was applied to measure the pressure drop of airflow through the sinter layer. The pressure measurement ranged from $0 \mathrm{~Pa}$ to $3000 \mathrm{~Pa}$. Six thermocouples were used to measure the variation in air temperature and were located from the bottom to the top of the sinter layer bed at intervals of $200 \mathrm{~mm}$. The outer wall of the device was wrapped with insulated Rockwool to reduce the amount of heat transmitted to the external environment. The air was continuously introduced by a centrifugal fan located at the bottom of the sinter bed, while a throttle valve was used to regulate the airflow rate through the vertical sinter bed. The heated sinter granules randomly fell onto the sinter bed until the appropriate height was attained. For the initial heat transfer between air and sinter granular material, the sinter granular material flew out with the assistance of a discharge device with a constant mass flow rate. 


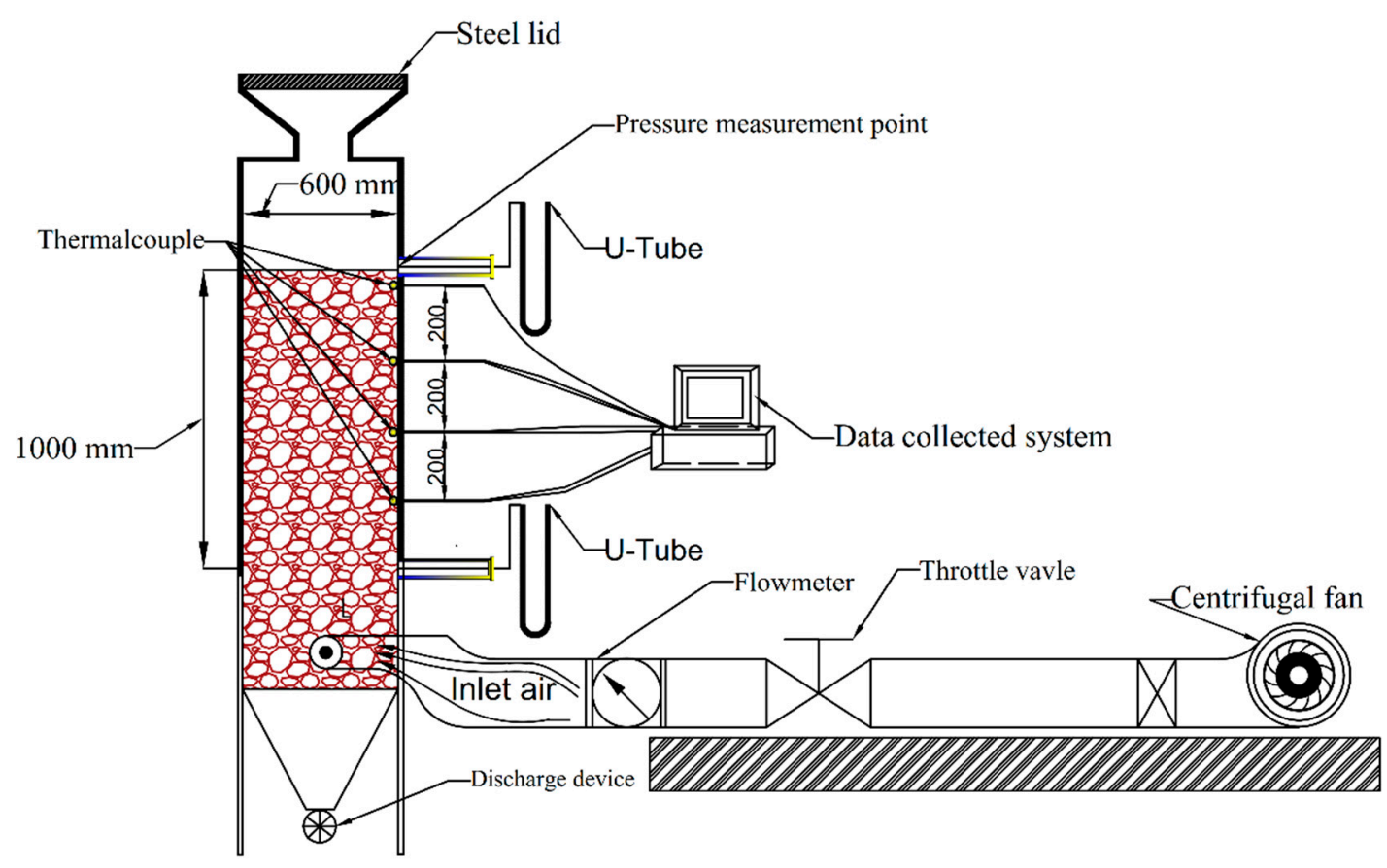

Figure 3. Schematic of the designed vertical sinter cooling bed experiment.

The air temperature and pressure drop were measured using a pilot design of an experimental sinter vertical bed (Figure 3), and the results are shown in Table 4. The air outlet temperature and air pressure drop were selected as target validation objects to compare the experimental data and results of the simulation. Five operating cases were used to compare the results from the simulated and measured devices, as illustrated in Table 4. The mean deviation of the air outlet temperature and pressure drop was $4.25 \%$ and $3.53 \%$, respectively, indicating that the calculated values were similar to the experimental measurements.

Table 4. Comparison of the results from the simulation and experiment.

\begin{tabular}{|c|c|c|c|c|c|c|c|c|c|c|}
\hline \multirow[b]{2}{*}{ Case } & \multirow{2}{*}{$T_{\mathrm{g}, \text { in }}$} & \multirow{2}{*}{$\begin{array}{c}M_{\mathrm{a}} \\
\left(\mathrm{m}^{3} \cdot \mathrm{h}^{-1}\right)\end{array}$} & \multirow{2}{*}{$\begin{array}{l}T_{\mathrm{s}, \text { in }} \\
\left({ }^{\circ} \mathrm{C}\right)\end{array}$} & \multirow{2}{*}{$\begin{array}{c}M_{\mathrm{s}} \\
\left(\mathrm{t} \cdot \mathrm{h}^{-1}\right)\end{array}$} & \multicolumn{3}{|c|}{ Pressure Drop (Pa) } & \multicolumn{3}{|c|}{ Air Outlet Temperature $\left({ }^{\circ} \mathrm{C}\right)$} \\
\hline & & & & & $\begin{array}{l}\text { Experimental } \\
\text { Results (Pa) }\end{array}$ & $\begin{array}{l}\text { Simulation } \\
\text { Results (Pa) }\end{array}$ & $\begin{array}{l}\text { Error } \\
(\%)\end{array}$ & $\begin{array}{l}\text { Experimental } \\
\text { Results }\left({ }^{\circ} \mathrm{C}\right)\end{array}$ & $\begin{array}{l}\text { Simulation } \\
\text { Results }\left({ }^{\circ} \mathrm{C}\right)\end{array}$ & $\begin{array}{l}\text { Error } \\
(\%)\end{array}$ \\
\hline 1 & 20 & 1024 & 550 & 1.2 & 632.6 & 648.06 & 2.44 & 344.7 & 357.56 & 3.73 \\
\hline 2 & 20 & 1204 & 600 & 1.3 & 850.7 & 852.33 & 0.2 & 359.7 & 347.42 & -3.42 \\
\hline 3 & 20 & 1355 & 600 & 1.2 & 1111.5 & 1004.43 & -9.63 & 298.7 & 312.79 & 4.72 \\
\hline 4 & 20 & 1144 & 550 & 1.2 & 796.2 & 763.53 & -4.10 & 309.5 & 328.30 & 6.07 \\
\hline 5 & 20 & 1084 & 580 & 1.0 & 716.2 & 725.36 & 1.28 & 351.2 & 362.86 & 3.32 \\
\hline
\end{tabular}

For a further analysis of the reliability of data obtained from the simulation, the dataset obtained from the vertical sinter beds in published reports is introduced in this section. The comparison of measured and calculated air outlet temperatures of the investigated vertical sinter bed is shown in Figure 4. The specific data obtained from the measured and simulated air outlet temperature are described in Table 5. The deviation of all cases used for validation was less than $5 \%$ and was consistent with the reported data. Therefore, the reliability of the simulated model analyzed in this study was verified and used to accurately describe the heat transfer performance of the vertical sinter cooling bed. 


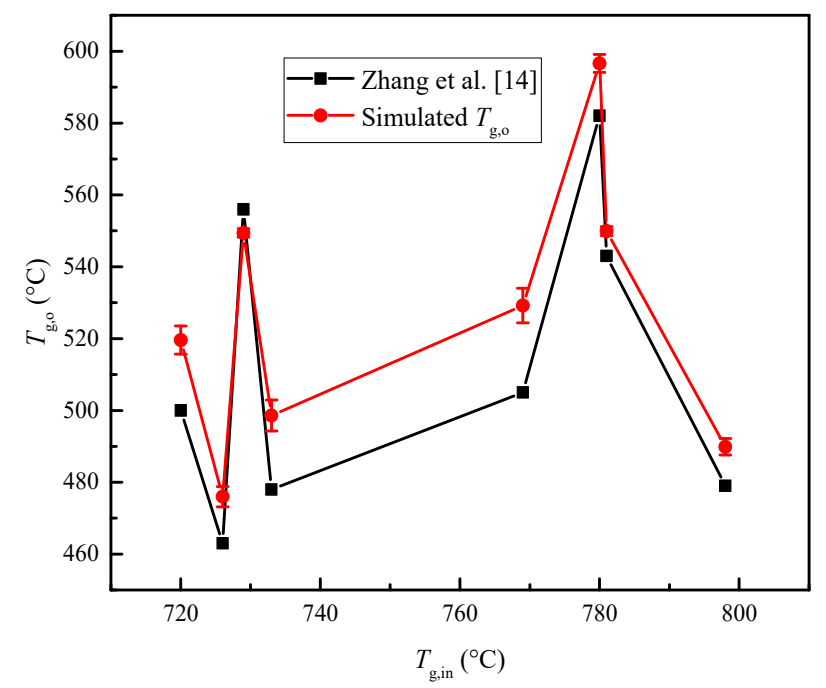

Figure 4. Comparison of the measured and calculated air outlet temperatures under different conditions (simulation and reported devices had identical operating and geometric conditions).

Table 5. The measured and simulated data and their deviations.

\begin{tabular}{cccc}
\hline Case & $\begin{array}{c}\text { Experimental Results } \\
\text { from the Study by } \\
\text { Zhang et al. [14] }\left({ }^{\circ} \mathbf{C}\right)\end{array}$ & $\begin{array}{c}\text { Results from the } \\
\text { Simulation Reported in } \\
\text { This Study }\left({ }^{\circ} \mathbf{C}\right)\end{array}$ & Error (\%) \\
\hline 1 & 479 & 489.9 & 2.28 \\
2 & 543 & 549.9 & 1.27 \\
3 & 582 & 596.6 & 2.51 \\
4 & 505 & 529.2 & 4.79 \\
5 & 478 & 498.6 & 4.31 \\
6 & 556 & 549.4 & -1.19 \\
7 & 463 & 476 & 2.80 \\
8 & 500 & 519.6 & 3.92 \\
\hline
\end{tabular}

\section{Results and Discussion}

Many factors affect the fluid flow and thermodynamic performance of a sinter bed for recovering heat wasted during sinter cooling. The simulation studied the geometric and operational parameters for the heat transfer process in a VSCB and compared them to the thermodynamic characteristics. According to the results from previous studies and actual production of a VSCB for a sinter cooling procedure, the operational and geometric factors play important roles in exergy transfer and fluid flow in a vertical sinter cooling process. The operational parameters, namely, the air mass flow rate, the cooling air inlet temperature, and sinter inlet mass flow rate, and the structural parameters, namely, the height and diameter of the sinter bed, are selected as important factors that significantly alter the fluid flow and heat transfer behaviors. Therefore, the investigation of the effect of geometric and operating parameters on the sinter cooling procedure in the VSCB is necessary.

\subsection{Effect of the Mass Flow Rate of Air}

The mass flow rate of air is an important parameter in the vertical sinter cooling process. After setting the five parameters to specific values, the variations of the outlet temperature and pressure drop in the cooling bed were obtained for airflow mass rates of $60,80,100,120$, and $140 \mathrm{~kg} \cdot \mathrm{s}^{-1}$, as shown in Figure 5. In this experiment, the sinter mass flow rate $\left(100 \mathrm{~kg} \cdot \mathrm{s}^{-1}\right)$, the effective height of the sinter bed $(6 \mathrm{~m})$, the diameter of the sinter bed $(10 \mathrm{~m})$, air inlet temperature $(293 \mathrm{~K})$, and sinter inlet temperature $(973 \mathrm{~K})$ were fixed. As shown in Figure 5, the air and sinter outlet temperatures peaked at $968 \mathrm{~K}$ and $512 \mathrm{~K}$, respectively, when the air mass flow rate was $60 \mathrm{~kg} \cdot \mathrm{s}^{-1}$. Moreover, the air outlet 
temperature was $935 \mathrm{~K}$ for an air mass flow rate of $80 \mathrm{~kg} \cdot \mathrm{s}^{-1}$, which exhibited a substantial decrease and an accelerated rate over the next three points to reach a temperature slightly higher than $648 \mathrm{~K}$ at $160 \mathrm{~kg} \cdot \mathrm{s}^{-1}$. However, the decreasing trend of the sinter outlet temperature was gradually decelerated. A potential explanation for this finding is that the increase in the air mass flow rate leads to an increase in the superficial velocity of air, and the volumetric heat transfer coefficient increases with an increase in air superficial velocity. When the sinter inlet heat flux was constant, the unit quantity of heat transfer between air and sinter granules decreased as the air mass flow rate increased, resulting in the deceleration of the decreasing trend of the sinter outlet temperature. When the cross-sectional area of VSCB was constant, the air mass flow rate increased with an increase in the superficial velocity of air. In accordance with the first law of thermodynamics, an increase in the mass flow rate led to a decrease in the air outlet temperature; however, the decreasing trend of the sinter outlet temperature decelerated and led to a substantial decrease in the air outlet temperature. Furthermore, the pressure drop of airflow through the sinter bed layer increased with an increasing air mass flow rate, as shown in Figure 5. The pressure drop of airflow increased by approximately 5 -fold when the air mass flow rate increased from 60 to $160 \mathrm{~kg} \cdot \mathrm{s}^{-1}$. The superficial velocity of air increased with an increase in air mass flow rate and positively correlated with the inertial and viscous terms within the pressure drop of airflow through the VSCB. Therefore, the increase in the superficial velocity of air led to an increase in the loss of airflow resistance.

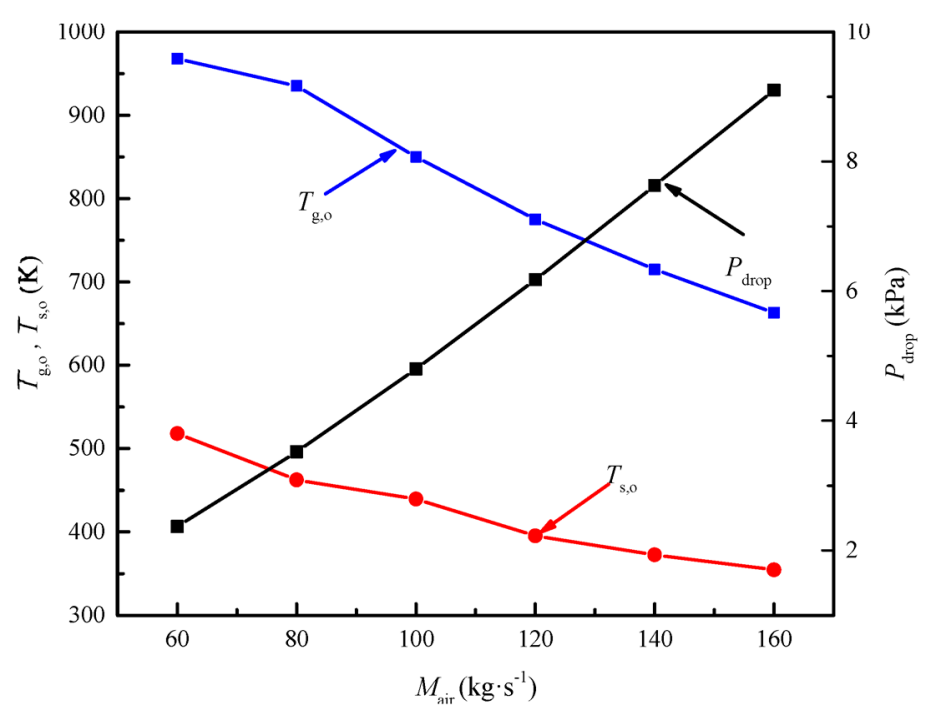

Figure 5. Effect of the air mass flow rate on the air and sinter outlet temperatures and the pressure drop of cooling air.

The air mass flow rate also affects the heat transfer and hydrodynamic performances, and thus the variations in the enthalpy exergy $E x$, temperature exergy $E x(T)$, and pressure exergy $E x(p)$ were measured for various air mass flow rates, as shown in Figure 6. The enthalpy exergy $E x$ and temperature exergy $E x(T)$ simultaneously increased at the beginning of the process until they reached the maximum value at $80 \mathrm{~kg} \cdot \mathrm{s}^{-1}$, and then decreased with an increased air mass flow rate. The maximum values of $E x(T)$ and $E x$ were $26.61 \mathrm{MJ} \cdot \mathrm{s}^{-1}$ and $26.36 \mathrm{MJ} \cdot \mathrm{s}^{-1}$, respectively. The difference between $E x(T)$ and $E x$ increased with an increase in the air mass flow rate, while the pressure $E x(p)$ decreased with an increase in the air mass flow rate. The increase in the air mass flow rate resulted in an increase in the superficial velocity of the air and a loss of airflow resistance. Therefore, the pressure exergy decreased with an increase in the air mass flow rate and subsequently increased the difference between $E x$ and $E x(T)$. 


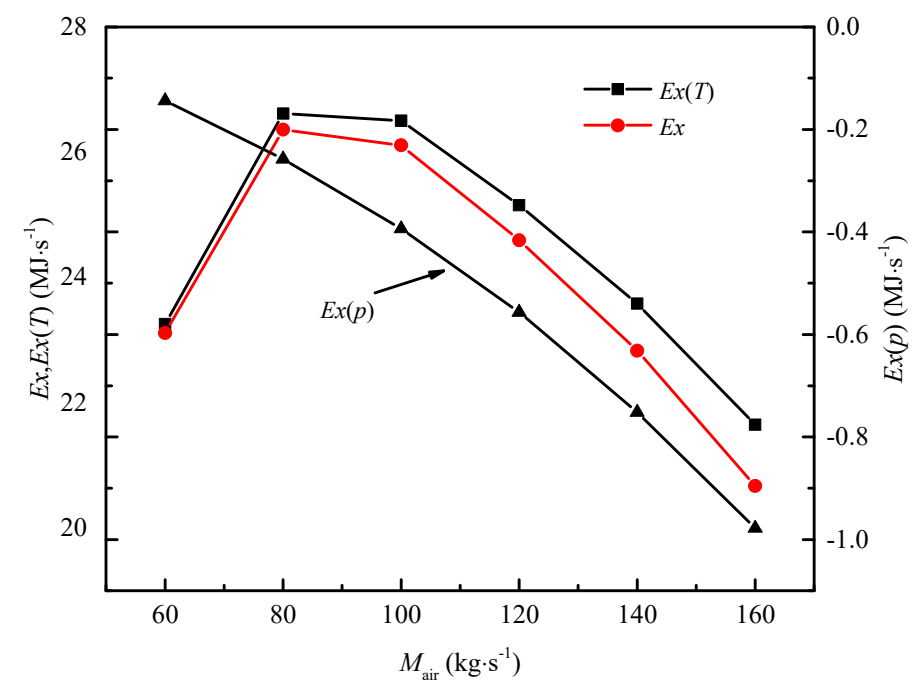

Figure 6. Effects of the air mass flow rate on enthalpy exergy $E x$, temperature exergy $E x(T)$, and pressure exergy $E x(p)$.

\subsection{Effect of the Air Inlet Temperature}

The variations in the air and sinter outlet temperatures and pressure drop of airflow in the sinter bed with changes in the air inlet temperature are depicted in Figure 7. Under this condition, a fixed sinter mass flow rate $(100 \mathrm{~kg} / \mathrm{s})$, the effective height of the sinter bed $(6 \mathrm{~m})$, the diameter of the sinter bed $(10 \mathrm{~m})$, air mass flow rate $(140 \mathrm{~kg} / \mathrm{s})$, and sinter inlet temperature $(973 \mathrm{~K})$ were used. The air and sinter outlet temperatures and pressure drop increased as the air inlet temperature increased because the increase in air inlet temperature increased the superficial velocity of air. However, a decreased cooling time between the gas and solid led to the inefficient transfer of heat between air and sinter, resulting in a linear increase in the sinter outlet temperature. The thermal energy transported in the sinter bed from the air inlet increased much faster than the energy transported out of bed by the sinter outlet, resulting in an increase in the air outlet temperature. Furthermore, when the increasing trend of the sinter outlet temperature presented linear growth, the increasing trend of air outlet temperature was gradually decelerated. In accordance with the first law of thermodynamics, the air and sinter outlet temperatures were increased by $5.3 \mathrm{~K}$ and $17 \mathrm{~K}$, respectively, if the air inlet temperature increased by $20 \mathrm{~K}$.

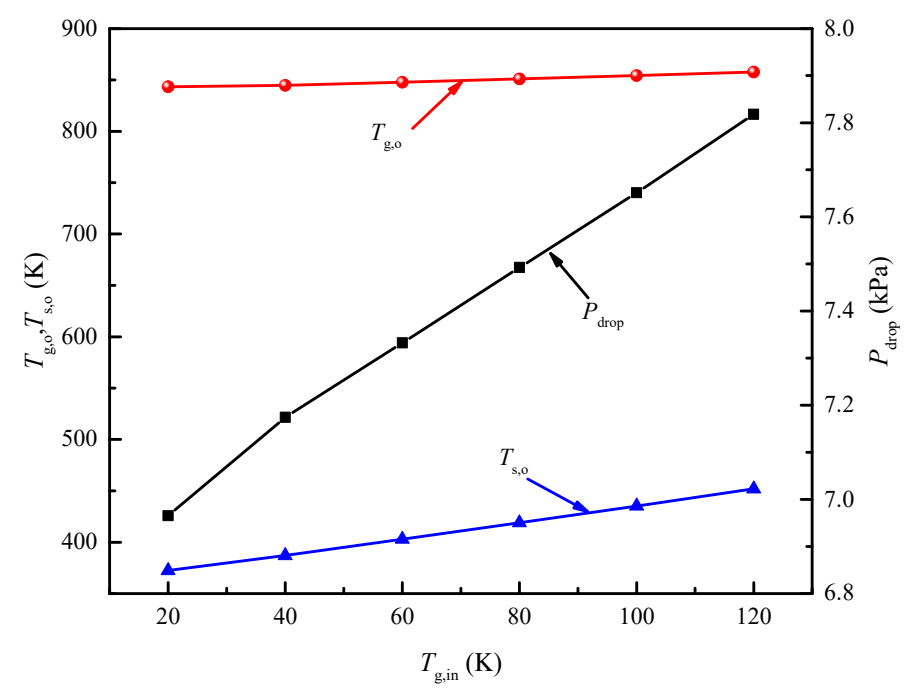

Figure 7. Effects of the air inlet temperature on the air and sinter outlet temperatures and the pressure drop of cooling air. 
The variations in the enthalpy exergy $E x$, temperature exergy $E x(T)$, and pressure exergy $E x(p)$ were calculated for various air inlet temperatures, as shown in Figure 8. The enthalpy exergy $E x$ and temperature exergy $E x(T)$ monotonically decreased with an increase in the air inlet temperature. The potential explanation for this result is that the increase in the air inlet temperature results in an increase in the air outlet temperature and, subsequently, an increase in air energy levels. As the air inlet temperature increased, the temperature difference between air and sinter granules decreased, leading to a decrease in the quality of the heat transfer process. Furthermore, as the air inlet temperature increased, the increase in the amplitude of the air energy level was smaller than gas-solid heat transfer recovery, leading to decreased $E x$. For every $20 \mathrm{~K}$ increase in the air inlet temperature, the enthalpy exergy $E x$ decreased by a mean of $2.37 \mathrm{MJ} \cdot \mathrm{s}^{-1}$. The pressure exergy $E x(p)$ gradually decreased with an increase in air inlet temperature because the increase in the air inlet temperature increased the air volume flow rate and resulted in a larger gas resistance loss, leading to a gradual decrease in pressure exergy $E x(p)$.

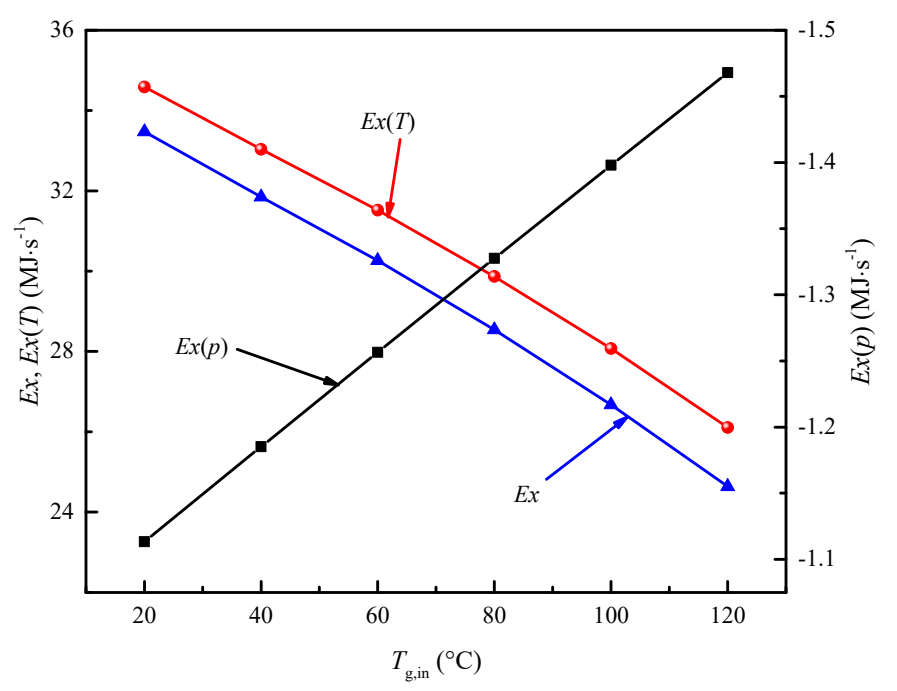

Figure 8. Effects of the air inlet temperature on enthalpy exergy $E x$, temperature exergy $E x(T)$, and pressure exergy $E x(p)$.

\subsection{Effect of the Sinter Mass Flow Rate}

In this section, the effect of the sinter mass flow rate on heat transfer and gas fluid performances was investigated. The variations in the air and sinter outlet temperatures and pressure drop with varying sinter import mass flow rate are depicted in Figure 9. The sinter import mass flow was set to $300 \mathrm{t} / \mathrm{h}$ to imitate the standard sinter production yield, whereas the other import mass flow rate was used to imitate the uncertainty and fluctuations during sinter production. The behavior of air and sinter outlet temperatures and pressure drop in the bed layer increased with an increase in the sinter import mass flow rate, as shown in Figure 9. The outlet temperature and pressure drop increased linearly with the increase in the sinter import mass flow rate. For each $5 \mathrm{t} / \mathrm{h}$ increase in the sinter import mass flow rate, the air and sinter outlet temperatures increased by a mean of $5.43 \mathrm{~K}$ and $4.08 \mathrm{~K}$, respectively, and the loss of air resistance increased by a mean of $21 \mathrm{~Pa}$. As the sinter import mass flow rate increased, a greater amount of thermal energy was carried in the sinter bed and increased the air and sinter temperatures, leading to increases in the superficial velocity of air in the sinter bed and the loss of air resistance. 


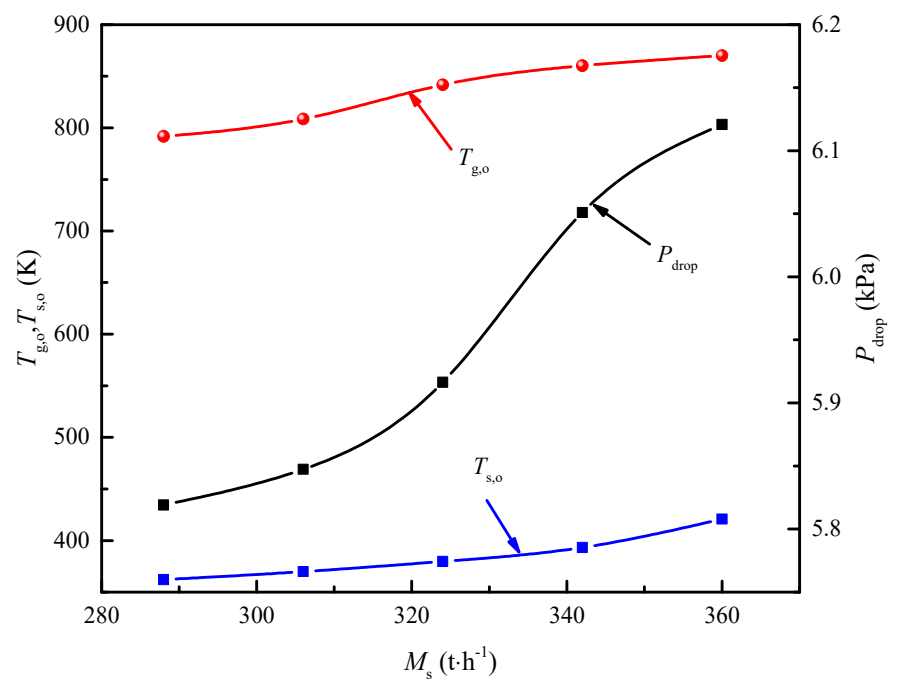

Figure 9. Effects of the sinter mass flow rate on the air and sinter outlet temperatures and pressure drop of cooling air.

The increases in enthalpy exergy $E x$ and temperature exergy $E x(T)$ with the increase in the sinter inlet mass flow rate are summarized in Figure 10. An increase in the sinter import mass flow rate might lead to an increase in the air outlet temperature and superficial velocity. The difference between the temperature exergy and enthalpy exergy remained constant, approximately from $288 \mathrm{t} / \mathrm{h}$ to $360 \mathrm{t} / \mathrm{h}$. For each $10 \mathrm{t} / \mathrm{h}$ increase in the sinter mass flow rate, the temperature and enthalpy exergy increased by a mean value of $1.12 \mathrm{MJ} \cdot \mathrm{s}^{-1}$ and $1.13 \mathrm{MJ} \cdot \mathrm{s}^{-1}$, respectively. Figure 10 also presents that the pressure exergy $E x(p)$ decreased as the sinter import mass flow rate increased. It was negatively correlated with the pressure drop, as the pressure drop of airflow increased with the sinter import mass flow rate, as reported in previous studies. Therefore, the increase in gas resistance loss led to a decrease in pressure exergy $\operatorname{Ex}(p)$.

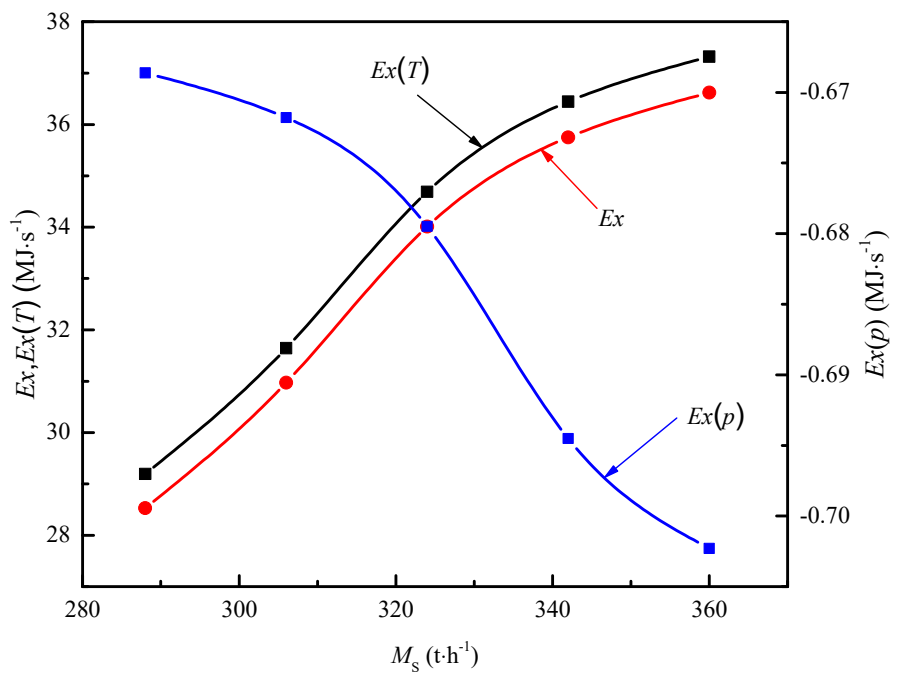

Figure 10. Effects of the sinter mass flow rate on enthalpy exergy $E x$, temperature exergy $E x(T)$, and pressure exergy $\operatorname{Ex}(p)$.

\subsection{Effect of the Diameter of the Sinter Bed}

The variations in air and sinter outlet temperatures and pressure drop of airflow with the diameter of the sinter bed are presented in Figure 11. As the diameter of the sinter bed increased, the air outlet temperature gradually increased and showed a decelerating rate. While the sinter outlet temperature 
steadily decreased, a flatter decreasing trend was observed. With the increase in the diameter of the sinter bed, an obvious increase in the decreasing velocity of the sinter flow rate was detected at the constant sinter production yield. The cooling time between air and sinter became longer, and the heat transfer was complete in the sinter bed. Thus, the air outlet temperature increased, and the sinter outlet temperature decreased. On the other hand, with the increase in the diameter of the sinter bed, a significant decrease in the superficial velocity of air was observed, which reduced the efficiency of heat transfer between the air and sinter. Thus, the cooling rate of hot sinter decreased, leading to a decreasing trend and deceleration of the sinter outlet temperature. As the diameter of the sinter bed continued to increase, the decreasing trend of sinter outlet temperature was slowing, and the increasing trend of the air outlet temperature decreased as well. Notably, as the diameter increased from 6 to $11 \mathrm{~m}$, the air outlet temperature increased by $14.2 \mathrm{~K}$ per meter, while the sinter outlet temperature decreased by $4 \mathrm{~K}$ per meter. As further shown in Figure 11, the pressure drop of airflow was substantially reduced as the diameter of the sinter bed increased. Because the superficial velocity of air decreased as the diameter of the sinter bed increased, as mentioned above, it further hindered the pressure drop of airflow. For each $1 \mathrm{~m}$ increase in the diameter, the average pressure drop increased by $4427 \mathrm{~Pa}$.

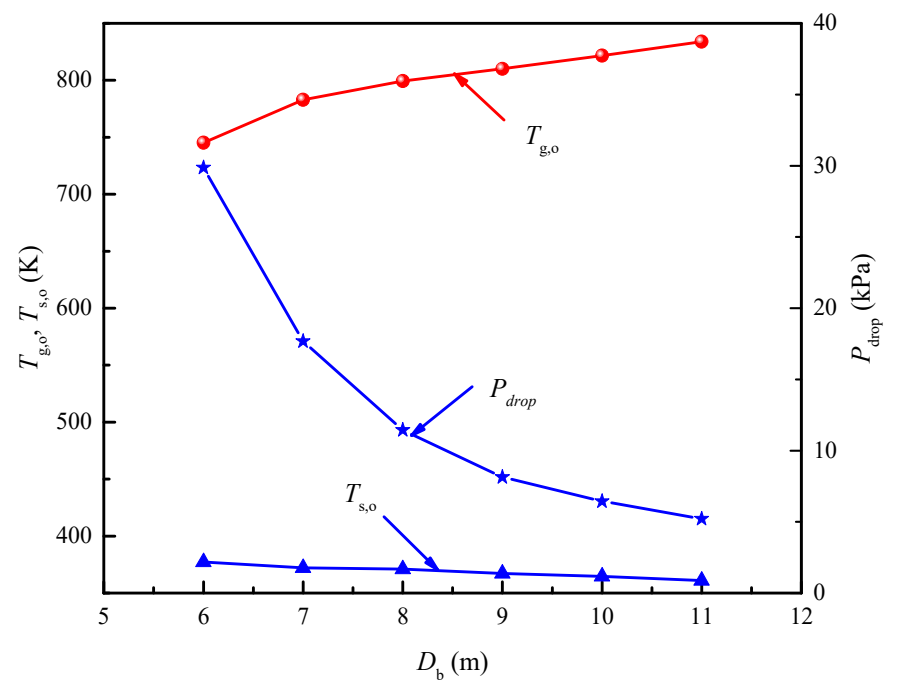

Figure 11. Effects of the diameter of the sinter bed on the air and sinter outlet temperatures and the pressure drop of cooling air.

Under this condition, the sinter mass flow rate $\left(100 \mathrm{~kg} \cdot \mathrm{s}^{-1}\right)$, effective height of the sinter bed $(6 \mathrm{~m})$, the air inlet temperature $(293 \mathrm{~K})$, air mass flow rate $(140 \mathrm{~kg} / \mathrm{s})$, and sinter inlet temperature (973 K) were fixed. The variations in the enthalpy exergy $E x$, temperature exergy $E x(T)$, and pressure exergy $E x(p)$ were obtained for various diameters of the sinter bed, as shown in Figure 12. The $E x, E x(T)$, and $E x(p)$ increased as the diameter of the sinter bed increased. An increase in the diameter likely increased the air outlet temperature and dramatically reduced the superficial velocity of air. As the pressure drop of airflow decreased, the pressure exergy $E x(p)$ in the sinter bed increased substantially. At the same time, an increase in the air outlet temperature led to a simultaneous increase in the temperature exergy $E x(T)$ and enthalpy exergy $E x$. For each $1 \mathrm{~m}$ increase in diameter, the temperature exergy $E x(T)$ and enthalpy exergy $E x$ increased by an average of $0.8 \mathrm{MJ} \cdot \mathrm{s}^{-1}$ and $1.4 \mathrm{MJ} \cdot \mathrm{s}^{-1}$, respectively. Furthermore, the increasing trend of pressure exergy $E x(p)$ was accelerated, which further limited the difference between the enthalpy exergy and temperature exergy as the diameter of the sinter bed steadily increased. 


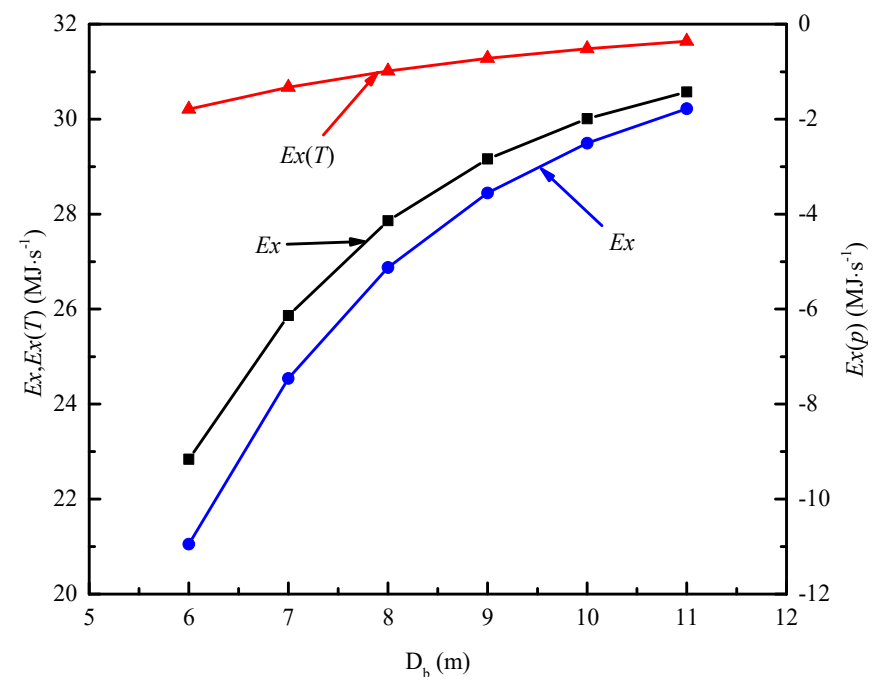

Figure 12. Effects of the diameter of the sinter bed on enthalpy exergy $E x$, temperature exergy $E x(T)$, and pressure exergy $E x(p)$.

\subsection{Effect of the Height of the Sinter Bed}

The effects of the height of the cooling sinter bed on the heat transfer and fluid flow of the sinter bed were analyzed. The variations in air and sinter outlet temperatures and pressure drop at various heights of the sinter bed are illustrated in Figure 13. When the height of the sinter bed increased, the air outlet temperature steadily increased, and a steady increasing trend was observed: the air outlet temperature increased by $67.8 \mathrm{~K}$ per meter. Furthermore, the sinter outlet temperature smoothly decreased, and a gradually decreasing trend was observed: the sinter outlet temperature decreased by $12.3 \mathrm{~K}$ per meter. As the height increased, the cooling time of heat transfer between the air and sinter would be prolonged, resulting in more sufficient heat transfer in the sinter bed, an increasing trend in the air outlet temperature, and a decreasing trend in the sinter outlet temperature. Moreover, the local temperature difference between the air and the sinter increased as the height of the sinter bed increased. A weaker heat transfer between air and sinter was observed, leading to a deceleration of the decreasing trend in the sinter outlet temperature. As shown in Figure 13, the pressure drop of the airflow stably increased when the height of the sinter bed increased. For each $1 \mathrm{~m}$ increase in height, the pressure drop of airflow increased by $1488.8 \mathrm{~Pa}$.

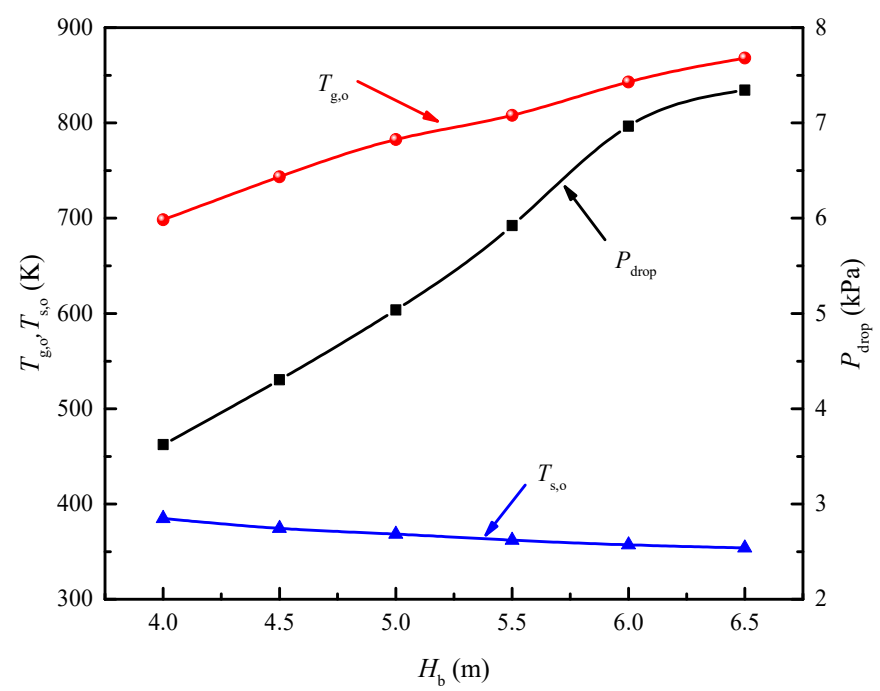

Figure 13. Effects of the height of the sinter bed on air and sinter outlet temperatures and the pressure drop of cooling air. 
The enthalpy exergy $E x$ and temperature exergy $E x(T)$ increased when the height of the sinter bed increased, and pressure exergy Ex(p) decreased as the height of the sinter bed increased, as shown in Figure 14. As the height of the sinter bed increased, the increasing rate of enthalpy exergy $E x$ slowed, but the pressure exergy $E x(p)$ decreased as the pressure drop of airflow increased. Furthermore, the increase in the rate of temperature exergy $E x(T)$ decelerated, which led to a greater difference between $E x$ and $E x(T)$. As a result, the increasing trend of the enthalpy exergy $E x$ of air decreased further.

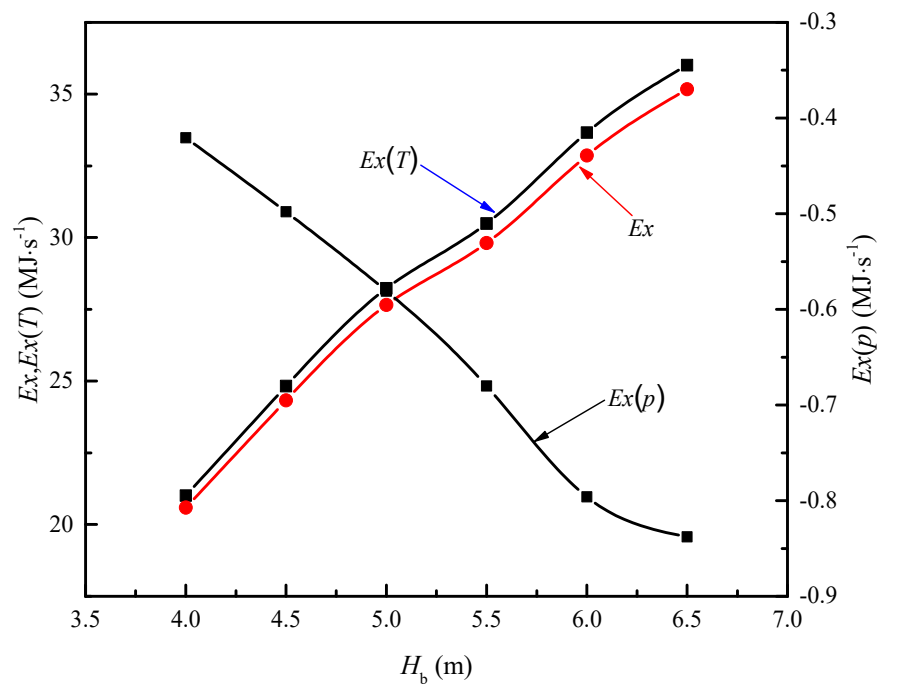

Figure 14. Effects of the height of the sinter bed on enthalpy exergy $E x$, temperature exergy $E x(T)$, and pressure exergy $E x(p)$.

\subsection{Optimization Modeling Procedure}

\subsubsection{Taguchi Method and ANOVA}

The Taguchi method is deemed as one of the popularly applied technical tools developed by Taguchi, which focuses on optimizing design experiments to determine the best factors and levels affecting the target response by reducing tedious and uneconomical computations and to obtain the order of importance of different factors for an objective response. The Taguchi method is the most effective optimization method to minimize the number of design experiments and contains full-factorial information from the fewest experiments with the help of orthogonal arrays. In this study, orthogonal arrays described the particular arrangement of factorial design experiments in terms of the factors being analyzed. Several parameters and their combinations were present in the vertical sinter bed that modulated the efficiency of the heat transfer process and must be analyzed to comprehensively understand the effects of factors of interest on the heat transfer and hydrodynamic performances in the sinter cooling process. Therefore, the factors of interest and the range of levels are presented in Table 6.

Table 6. Parameters and levels considered in this study.

\begin{tabular}{ccccccc}
\hline Label & Factor & Level 1 & Level 2 & Level 3 & Level 4 & Level 5 \\
\hline A & Air inlet temperature, $T_{\mathrm{g}, \text { in }}\left({ }^{\circ} \mathrm{C}\right)$ & 20 & 40 & 60 & 80 & 100 \\
B & Sinter mass flow rate, $m_{\mathrm{S}}\left(\mathrm{kg} \cdot \mathrm{h}^{-1}\right)$ & 288 & 306 & 324 & 342 & 360 \\
$\mathrm{C}$ & Height of the sinter bed, $H_{\mathrm{b}}(\mathrm{m})$ & 4 & 4.5 & 5 & 5.5 & 6 \\
$\mathrm{D}$ & Diameter of the sinter bed, $D_{\mathrm{b}}(\mathrm{m})$ & 6 & 7 & 8 & 9 & 10 \\
$\mathrm{E}$ & Air mass flow rate, $M_{\mathrm{a}}\left(\mathrm{kg} \cdot \mathrm{h}^{-1}\right)$ & 60 & 80 & 100 & 120 & 140 \\
\hline
\end{tabular}

The choice of an appropriate orthogonal array is an essential step of a statistical analysis, which is determined by the degree of freedom (DOF) theory [33]. The calculations from the $\mathrm{L}_{25}\left(5^{5}\right)$ orthogonal experiments were applied to identify the effects of factors and their levels on the target 
value. The corresponding results and signal to noise ratios are described in Table 7. According to previous studies, the air inlet temperature, sinter mass flow rate, height of the sinter bed, diameter of the sinter bed, and air mass flow rate were used for optimization.

Table 7. $P_{\text {drop }}{ }^{1}$ and $E x^{2}$ variation with their $\mathrm{S} / \mathrm{N}$ ratios for the $\mathrm{L}_{25}\left(5^{5}\right)$ orthogonal array.

\begin{tabular}{|c|c|c|c|c|c|c|c|c|c|}
\hline \multicolumn{10}{|c|}{ Parameters } \\
\hline \multirow[b]{2}{*}{ Case } & \multirow{2}{*}{$\mathbf{A}$} & \multirow[t]{2}{*}{ B } & \multirow{2}{*}{$\begin{array}{c}\mathrm{C} \\
\text { rels }\end{array}$} & \multirow[t]{2}{*}{ D } & \multirow[t]{2}{*}{$\mathrm{E}$} & \multicolumn{2}{|c|}{ Results } & \multicolumn{2}{|c|}{ S/N Ratio } \\
\hline & & & & & & $P_{\text {drop }}(\mathrm{Pa})$ & $E x(\mathrm{MJ} / \mathrm{s})$ & $P_{\text {drop }}$ & $E x$ \\
\hline 1 & 1 & 1 & 1 & 1 & 1 & 8755.5 & 6.5482 & -78.8456 & 16.3225 \\
\hline 2 & 1 & 2 & 2 & 2 & 2 & 7441.4 & 12.5810 & -77.4331 & 21.9943 \\
\hline 3 & 1 & 3 & 3 & 3 & 3 & 7693.6 & 18.8894 & -77.7226 & 25.5243 \\
\hline 4 & 1 & 4 & 4 & 4 & 4 & 7820.4 & 21.9384 & -77.8645 & 26.8241 \\
\hline 5 & 1 & 5 & 5 & 5 & 5 & 8328.9 & 31.9316 & -78.4118 & 30.0844 \\
\hline 6 & 2 & 1 & 2 & 3 & 4 & 9293.0 & 11.8293 & -79.3632 & 21.4592 \\
\hline 7 & 2 & 2 & 3 & 4 & 5 & 9628.7 & 18.7338 & -79.6713 & 25.4525 \\
\hline 8 & 2 & 3 & 4 & 5 & 1 & 3533.0 & 19.0416 & -70.9629 & 25.5941 \\
\hline 9 & 2 & 4 & 5 & 1 & 2 & $15,186.1$ & 13.4019 & -83.6289 & 22.5433 \\
\hline 10 & 2 & 5 & 1 & 2 & 3 & 8812.9 & 9.4028 & -78.9024 & 19.4651 \\
\hline 11 & 3 & 1 & 3 & 5 & 2 & 3980.3 & 20.0077 & -71.9982 & 26.0239 \\
\hline 12 & 3 & 2 & 4 & 1 & 3 & $20,088.1$ & 8.5193 & -86.0588 & 18.6081 \\
\hline 13 & 3 & 3 & 5 & 2 & 4 & $17,377.0$ & 14.9978 & -84.7995 & 23.5206 \\
\hline 14 & 3 & 4 & 1 & 3 & 5 & $10,244.7$ & 7.8339 & -80.2100 & 17.8796 \\
\hline 15 & 3 & 5 & 2 & 4 & 1 & 3673.5 & 19.0797 & -71.3017 & 25.6114 \\
\hline 16 & 4 & 1 & 4 & 2 & 5 & $22,327.3$ & 10.1193 & -86.9767 & 20.1030 \\
\hline 17 & 4 & 2 & 5 & 3 & 1 & 6193.2 & 12.6987 & -75.8383 & 22.0752 \\
\hline 18 & 4 & 3 & 1 & 4 & 2 & 4158.4 & 17.5610 & -72.3785 & 24.8910 \\
\hline 19 & 4 & 4 & 2 & 5 & 3 & 4790.2 & 19.5364 & -73.6071 & 25.8169 \\
\hline 20 & 4 & 5 & 3 & 1 & 4 & $23,299.2$ & 5.9202 & -87.3468 & 15.4467 \\
\hline 21 & 5 & 1 & 5 & 4 & 3 & 8939.5 & 17.5114 & -79.0263 & 24.8664 \\
\hline 22 & 5 & 2 & 1 & 5 & 4 & 7036.6 & 12.0931 & -76.9473 & 21.6507 \\
\hline 23 & 5 & 3 & 2 & 1 & 5 & $27,668.0$ & 3.2545 & -88.8396 & 10.2497 \\
\hline 24 & 5 & 4 & 3 & 2 & 1 & 7677.1 & 10.2764 & -77.7039 & 20.2368 \\
\hline 25 & 5 & 5 & 4 & 3 & 2 & 6893.1 & 22.4590 & -76.7682 & 27.0278 \\
\hline
\end{tabular}

According to the Taguchi method, three criteria determine optimization: higher is better, normal is better, and lower is better. In the present study, the higher is better criterion was applied to describe the heat transfer performance, and the lower is better criterion was employed to present the hydrodynamic performance in the sinter cooling process [34].

$$
\begin{aligned}
& \mathrm{S} / \mathrm{N}=10 \log \frac{1}{\mathrm{n}}\left(\sum y^{2}\right) \\
& \mathrm{S} / \mathrm{N}=-10 \log \frac{1}{\mathrm{n}}\left(\sum \mathrm{y}^{2}\right)
\end{aligned}
$$

where $y$ is the mean value of the response function, and $n$ is the number of factors analyzed in the experiment. 
A response table was constructed to describe the mean $\mathrm{S} / \mathrm{N}$ (signal to noise) ratio and the significance level of factors and to obtain a comprehensive understanding of the effects of design factors on the response function, as shown in Table 8, for air outlet exergy. As described above, the criteria used in the statistical method to analyze the heat transfer performance was higher is better. Therefore, the greatest variation in the range of the $\mathrm{S} / \mathrm{N}$ ratio (delta value) represented the most important factor in the corresponding response function. Thus, the best performance level of each factor had the largest value of the $\mathrm{S} / \mathrm{N}$ ratio. As shown in Table 8, the most effective factor was the diameter of the bed, followed by the airflow rate and height of the bed. The optimal combination of factors for the air outlet exergy response was $A_{1} B_{5} C_{5} D_{5} E_{2}$.

Table 8. Factorial effects and weight factors for the exergy of air outlet recovery.

\begin{tabular}{cccccc}
\hline Level & A & B & C & D & E \\
\hline 1 & $24.15^{1}$ & 21.76 & 20.04 & 16.63 & 21.97 \\
\hline 2 & 22.90 & 21.96 & 21.03 & 21.06 & $\begin{array}{c}24.50 \\
1\end{array}$ \\
\hline 3 & 22.33 & 21.96 & 22.54 & 22.79 & 22.86 \\
\hline 4 & 21.67 & 22.66 & 23.63 & 25.53 & 21.78 \\
\hline 5 & 20.81 & 23.53 & 24.62 & 25.83 & 20.75 \\
1 & & 1 & 1 & \\
\hline Delta & 3.34 & 1.77 & 4.58 & 9.20 & 3.74 \\
\hline$\sum$ Delta & 22.63 & & & & \\
\hline Weight & $48.71 \%$ & & & \\
\hline \multicolumn{5}{c}{ represent the optimal levels. }
\end{tabular}

The Taguchi method was used to analyze the effects of design factors on the pressure drop as a response. In Table 9, the diameter of the bed $\left(D_{\mathrm{b}}\right)$ was the main factor contributing to the response compared with other factors, and a better performance level was attributed to the higher $\mathrm{S} / \mathrm{N}$ ratio among the five levels for each factor. Thus, the optimized combination of factors and levels were determined as $\mathrm{A}_{1} \mathrm{~B}_{5} \mathrm{C}_{1} \mathrm{E}_{5} \mathrm{D}_{1}$ for the pressure drop as a response function.

Table 9. Factorial effects and weight factors for the pressure drop.

\begin{tabular}{cccccc}
\hline Level & A & B & C & D & E \\
\hline 1 & $-78.06^{1}$ & -79.24 & $-77.46^{1}$ & -84.94 & $-74.93^{1}$ \\
\hline 2 & -78.51 & -79.19 & -78.11 & -81.16 & -76.44 \\
\hline 3 & -78.87 & -78.94 & -78.89 & -77.98 & -79.06 \\
\hline 4 & -79.23 & -78.60 & -79.73 & -76.05 & -81.26 \\
\hline 5 & -79.86 & $-78.55^{1}$ & -80.34 & $-74.39^{1}$ & -82.82 \\
\hline Delta & 1.80 & 0.70 & 2.88 & 10.56 & 7.89 \\
\hline$\sum$ Delta & 23.83 & & & \\
\hline Weight & $51.29 \%$ & &
\end{tabular}

\subsubsection{Analysis of Variance (ANOVA)}

ANOVA is a statistical analysis method developed by Ronald Fisher that divides aggregate variations in the observed data (response measurement) into two portions: systematic portions and random portions. The systematic portions and random portions are determined by varying factors being tested in the experiments. ANOVA is applied to determine the effects of independent variables 
(the various factors of interest) on the dependent variable (the response of physical phenomenon) in statistical analysis. Tables 10 and 11 present the results of the ANOVA for air outlet exergy and pressure drop, respectively. The results of ANOVA are presented in tables, and the effect of design factors on the air outlet exergy was reported as F-values and 95\% confidence intervals. In this situation, if $\mathrm{F}_{0.05}$ $(4.4)>6.388$, according to the deciding value for the $95 \%$ confidence interval and 5\% significance level, the amplitude of the variation in the tested factors would affect the air outlet exergy and pressure drop. The criteria for determining the effect of a design factor on response function mainly depends on the magnitude of the F-value. The design factor with the highest F-value represents the factor with the most significant effect on the response function.

Table 10. ANOVA of air outlet exergy.

\begin{tabular}{cccccc}
\hline Parameters & D.O.F. $^{\mathbf{1}}$ & Sum of Squares & Variance & F-Value & Contribution (\%) \\
\hline A & 4 & 93.92 & 23.48 & 1.73 & 9.37 \\
\hline B & 4 & 73.72 & 18.43 & 1.36 & 7.35 \\
\hline C & 4 & 163.66 & 40.92 & 3.01 & 16.32 \\
\hline D & 4 & 569.48 & 142.37 & 10.49 & 56.79 \\
\hline E & 4 & 47.68 & 11.92 & 0.88 & 4.75 \\
\hline Error & 4 & 54.30 & 13.57 & & 5.42 \\
\hline Total & 24 & 1002.76 & & \\
\hline & & 1 &
\end{tabular}

Table 11. ANOVA for the pressure drop.

\begin{tabular}{cccccc}
\hline Parameters & D.O.F. & Sum of Squares & Variance & F-Value & Contribution (\%) \\
\hline A & 4 & $60,096,530$ & $15,024,133$ & 5.98 & 5.66 \\
\hline B & 4 & $23,128,912$ & $5,782,228$ & 2.30 & 2.18 \\
\hline C & 4 & $52,139,995$ & $13,034,999$ & 5.19 & 4.91 \\
\hline D & 4 & $605,712,033$ & $151,428,008$ & 60.29 & 57.08 \\
\hline E & 4 & $310,112,770$ & $77,528,193$ & 30.87 & 29.22 \\
\hline Error & 4 & $10,046,182$ & $2,511,546$ & & 0.95 \\
\hline Total & 24 & $1,061,236,423$ & & & 100.00 \\
\hline
\end{tabular}

The mathematical description of the ANOVA, such as a sum of squares (SS), mean of squares (MS), degree of freedom (DOF), and F-values, are calculated using Equations (19)-(26):

$$
\begin{gathered}
C F=\frac{\left(\sum y_{i}\right)^{2}}{m} \\
S S_{\text {factor }}=\frac{\sum y_{\text {factor }-i}^{2}}{N}-C F \\
S S_{T}=\sum y_{i}^{2}-C F \\
S S_{e}=S S_{T}-\sum S S_{A} \\
d f_{\text {total }}=n-1 \\
d f_{\text {factor }}=k-1 \\
V_{\text {factor }}=\frac{S S_{\text {factor }}}{d f_{\text {factor }}}
\end{gathered}
$$




$$
F_{\text {factor }}=\frac{V_{\text {factor }}}{V_{\text {error }}}
$$

where $C F$ is the correction factor, $y_{i}$ is the factors tested in the $i^{\text {th }}$ case, $\mathrm{m}$ is the total number of cases, $S S_{\text {factor }}$ is the total of squares of a single factor, $y_{\text {factor }-i}$ is the $i^{\text {th }}$ level of the factor of interest, $\mathrm{N}$ is the total number of levels of the factor of interest, $S S_{\mathrm{T}}$ is the sum of squares of variation, $S S_{e}$ is the total of squares due to error, $S S_{A}$ is the sum of squares of factor $A, f_{\text {total }}$ is the total DOF, $n$ is the number of standard experiments, $f_{\text {factor }}$ is the DOF for a single factor, $\mathrm{k}$ is the total number of levels of a single factor, $F_{\text {factor }}$ is the F-value of factor, and $V_{\text {factor }}$ and $V_{\text {error }}$ are the sum of squares of a single factor and error function, respectively.

In this section, ANOVA was applied to analyze the effects of various design factors on a single response function. The method introduced in this study had two advantages: (1) the contribution rate and most significant parameters were obtained by analyzing the variations in design factors, and (2) the reliability of the results of the Taguchi analysis method was verified. As shown in Table 10, the diameter of the bed was the most significant factor affecting the heat transfer performance, with a contribution rate of $56.79 \%$, followed by the height of the bed and air inlet temperature, with contribution rates of $16.32 \%$ and $9.37 \%$, respectively. The air mass flow rate exerted little effect on the exergy recovered. According to the magnitude of the contribution rate for each factor, the significance of the design factors was determined as $D_{\mathrm{b}}>H_{\mathrm{b}}>T_{\mathrm{g}, \text { in }}>M_{\mathrm{s}}>M_{\mathrm{a}}$, consistent with the results acquired from the Taguchi method. The quantitative description of the effect of each factor on the air outlet exergy and contribution rates are presented in Figure 15. In addition, the contribution rates of design factors to the response of pressure drop determined using ANOVA are presented in Table 11. As shown in Table 11, the diameter of the bed exerted the greatest effect on the pressure drop, with a contribution rate of $57.08 \%$, followed by the airflow rate $(29.22 \%)$ and air inlet temperature $(5.66 \%)$. The sinter flow rate and height of the bed exerted a limited effect on the hydrodynamic performance of the vertical sinter cooling bed. The contribution rate of error was $0.95 \%$, which comprised of three error parts, such as calculation error, external sources of error, and uncontrollable error. The contribution of each factor to air pressure is presented in Figure 16.

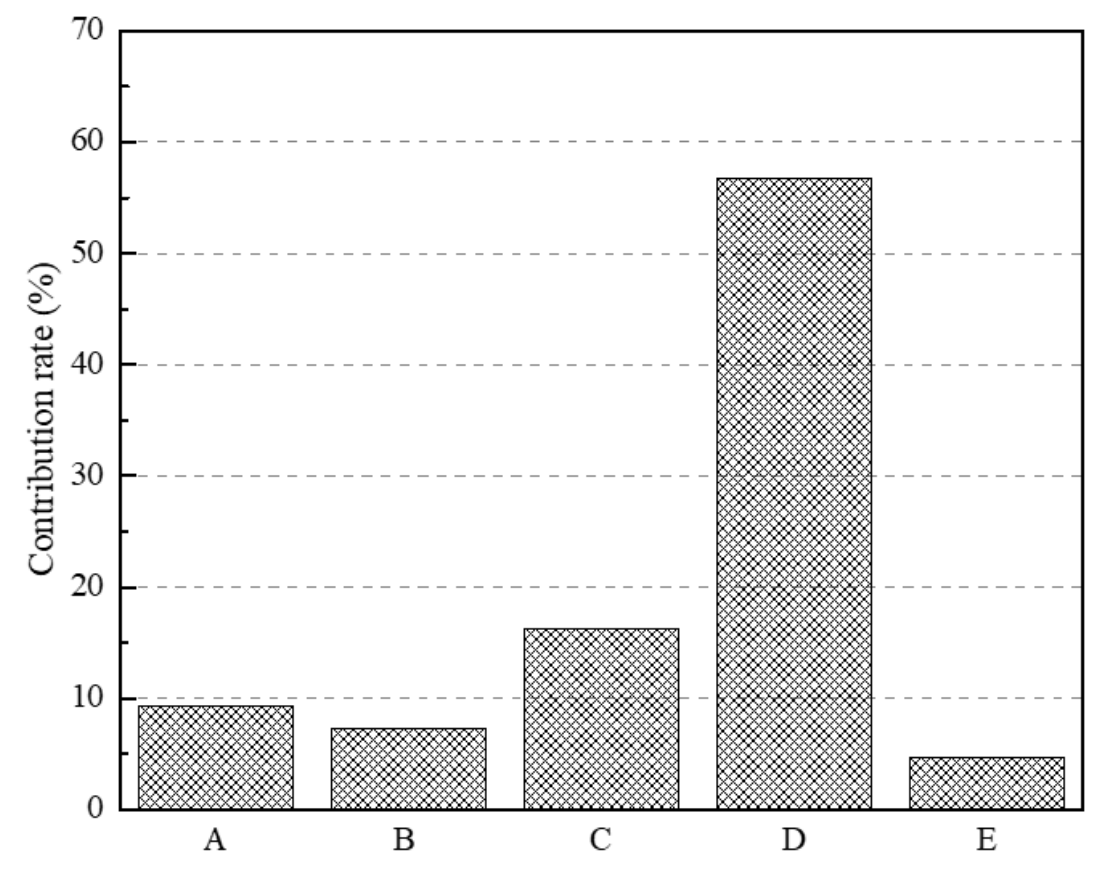

Figure 15. Contributions of each factor to the exergy of air outlet recovery. 


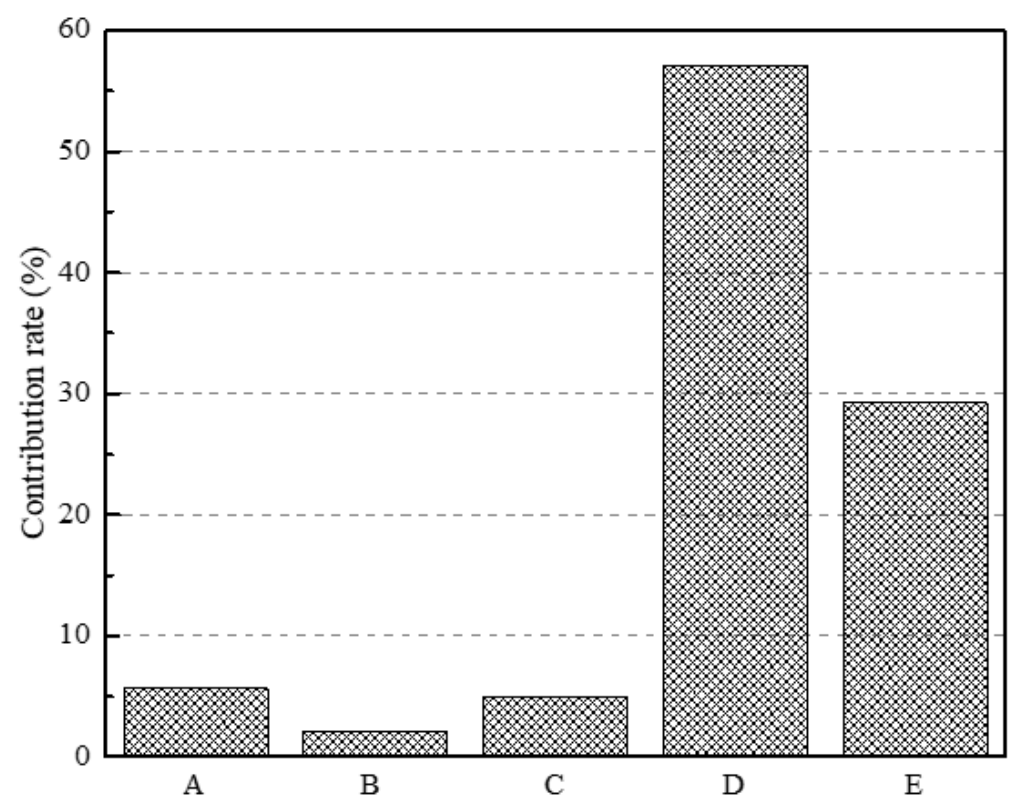

Figure 16. Contributions of each factor to the pressure drop.

\subsection{The Multi-Object Optimization Method}

\subsubsection{Grey Relational Analysis (GRA)}

In the actual industry, production is usually required to meet multi-objective target functions, and thus the Taguchi method maybe not suitable to optimize the multi-objective performance. The Taguchi grey relational method is applied to determine the order of importance of design factors in modulating the performance of multiple objective characteristics, reveal the effect of geometric and operating factors on the heat transfer performance characteristics of a vertical sinter cooling bed, and overcome the limitation of the Taguchi analysis that is only suitable for a single response function. The advance of the GRA method is the ability to convert the bi-objective or multi-objective target optimization into a single target optimization problem. In this section, the GRA method was employed for optimization to simultaneously improve the heat transfer and hydrodynamic performance in the vertical sinter cooling process.

Based on the published literature, five factors-the airflow mass flow rate, air inlet temperature, sinter mass flow rate, height of the bed, and diameter of the bed-were chosen to optimize the performance characteristics. Two criteria had been established for the simultaneous optimization analysis: higher is better for describing heat transfer performance (air outlet exergy), and the lowest is better for the hydrodynamic performance (air pressure drop). The mathematical description of criteria for higher is better and the lowest is better is shown in Equation (27) and Equation (28), respectively.

$$
\begin{aligned}
& y_{i}(k)=\frac{x_{i}(k)-\min x_{i}(k)}{\max x_{i}(k)-\min x_{i}(k)} \\
& y_{i}(k)=\frac{\max x_{i}(k)-x_{i}(k)}{\max x_{i}(k)-\min x_{i}(k)}
\end{aligned}
$$

The value of the grey relational grade calculated from the grade relational coefficient for each response must be calculated. The grade relational coefficient determines the relation between comparative and referenced normalized value. Equations (28)-(31) are used to describe the grade relational coefficient:

$$
\xi_{i}(k)=\frac{\Delta_{\min }+\rho \Delta_{\max }}{\Delta_{0 i}(k)+\rho \Delta_{\max }}
$$




$$
\begin{gathered}
\Delta_{0 i}=\left\|y_{0}(k)-y_{i}(k)\right\| \\
\Delta_{\max }=\max _{\forall j \in i} \max _{\forall k}\left\|y_{0}(k)-y_{i}(k)\right\| \\
\Delta_{\min }=\min _{\forall j \in i} \min _{\forall k}\left\|y_{0}(k)-y_{i}(k)\right\|
\end{gathered}
$$

where $\Delta_{0 i}$ is the value of the deviation between comparative and reference sequences, $y_{i}(k)$ and $y_{0}(k)$ are the comparative and references sequences, respectively. $\Delta_{\min }$ and $\Delta_{\min }$ are the minimum and maximum values of $\Delta_{0 i}$, respectively. $\rho$ is the identification coefficient that ranges from 0 to 1 . According to previous studies using GRA, the use of an arbitrary value for the identification coefficient ranging from 0 to 1 does not affect the sequence of the significance of the factors. Consistent with the conclusions of many research papers, $\rho$ was equal to 0.5 in this study.

Notably, the applicable method for determining the weight factor for each response function in GRA that is significant obtains the reliability of the results of the grey relational grade. In a previous study, factors were assigned equal weight factors in the multiple response functions to describe the relation of the grey relational coefficient for different responses, but it may not be a reliable method. In actual industrial production, the weight of each factor contributing to multiple physical phenomena differs. Therefore, a reliable method must be introduced to determine the weight factors for different responses based on the effects of various factors of interest on the performance in the vertical sinter cooling process.

$$
\gamma_{i}=\frac{1}{n} \sum_{k=1}^{n} w_{k} \xi_{i}(k)
$$

where $\gamma_{i}$ is the grey relational grade for each combination orthogonal experiment, $w_{k}$ is the weight factor for $k$ th response function, and $\mathrm{n}$ is the number of response functions.

The mean $\mathrm{S} / \mathrm{N}$ ratio scale of each factor represents the order of significance in the statistical analysis. The calculated delta value is applied to determine the most effective factor for each response function that is equal to the largest value minus the smallest value of the $\mathrm{S} / \mathrm{N}$ ratio for each factor. The delta value for each factor is calculated to obtain the sum of delta values for each response function. The weight factor for each response is determined by calculating the ratio of the total of delta value for each response to the sum of delta values for all responses. The mathematical process is described in Equation (34):

$$
w_{i}=\frac{\sum_{i=1}^{n} \text { Delta }_{i, j}}{\sum_{j=1}^{m} \sum_{i=1}^{n} \text { Delta }_{i, j}}
$$

where $m$ is the total number of response functions (in this study, the total number of responses was two), $n$ is the number of the factors for each response function, and Delta describes the range from largest to smallest values of the $\mathrm{S} / \mathrm{N}$ ratio for each factor.

According to Equation (34), the weight factor is calculated for each response function. The weight factors of air outlet exergy and pressure drop were $48.71 \%$ and $51.29 \%$, respectively. The weight factor for air outlet exergy and pressure drop are listed in Tables 8 and 9, respectively. The grey relational grade is described as follows by considering weight factors:

$$
G R G=0.4871 * G R C_{E_{\mathrm{x}}}+0.5129 * G R C_{p_{\text {drop }}}
$$

where $G R C_{P}$ and $G R C_{E x}$ represent the grey relational coefficient of the pressure drop and air outlet exergy, respectively.

As mentioned above, a significant advantage of the grey relational grade method is that it converts the two response functions (increasing air outlet exergy and reducing pressure drop) to a single target function (multi-objective performance). The GRA method is used for the optimization process to simultaneously improve multiple performance characteristics of a vertical sinter cooling bed. Table 12 shows the calculated values for normalized results, grey relational coefficients, grey relational grades, 
and the order of significance for GRA. The grey relational grade is calculated using Equation (34). The variations in the grey relational grade and corresponding $\mathrm{S} / \mathrm{N}$ ratios are described in Figure 17. The case combining all considered factors, which exhibited the maximum grey relational grade, performed the best in terms of multiple performance characteristics. As shown in Table 7, case 5 $\left(A_{1} B_{5} C_{5} D_{5} E_{5}\right)$ exhibited the best performance for multiple characteristics. Under the condition of the combination of factors included in case 5, the air outlet exergy and pressure drop of the vertical sinter cooling bed were $32.2 \mathrm{MJ} \cdot \mathrm{s}^{-1}$ and $8328.9 \mathrm{~Pa}$, respectively. In addition, the smallest grey relational grade was obtained for the combination of factors in case $23\left(\mathrm{~A}_{5} \mathrm{~B}_{3} \mathrm{C}_{2} \mathrm{D}_{1} \mathrm{E}_{5}\right)$. In this situation, the air outlet exergy and pressure drop of the cooling bed were $4.08 \mathrm{MJ} \cdot \mathrm{s}^{-1}$ and $27668 \mathrm{~Pa}$, respectively.

Table 12. Normalized results, grey relational coefficient, grey relational grade, and order.

\begin{tabular}{|c|c|c|c|c|c|c|}
\hline \multirow{2}{*}{ Case } & \multicolumn{2}{|c|}{ Normalized Results } & \multicolumn{2}{|c|}{ Grey Relational Coefficients } & \multirow{2}{*}{ Grey Relational Grade } & \multirow{2}{*}{ Order } \\
\hline & $P_{\text {drop }}$ & $E x$ & $P_{\text {drop }}$ & $E x$ & & \\
\hline 1 & 0.78362 & 0.11486 & 0.69795 & 0.36097 & 0.533815 & 18 \\
\hline 2 & 0.83806 & 0.32522 & 0.75536 & 0.42561 & 0.594745 & 13 \\
\hline 3 & 0.82761 & 0.54520 & 0.74362 & 0.52367 & 0.636486 & 9 \\
\hline 4 & 0.82236 & 0.65153 & 0.73785 & 0.58929 & 0.665493 & 8 \\
\hline 5 & 0.80129 & 1.00000 & 0.71560 & 1.00000 & 0.854127 & 1 \\
\hline 6 & 0.76134 & 0.29901 & 0.67690 & 0.41632 & 0.549980 & 16 \\
\hline 7 & 0.74743 & 0.53978 & 0.66439 & 0.52071 & 0.594410 & 14 \\
\hline 8 & 1.00000 & 0.55051 & 1.00000 & 0.52660 & 0.769416 & 2 \\
\hline 9 & 0.51717 & 0.35385 & 0.50874 & 0.43624 & 0.473426 & 20 \\
\hline 10 & 0.78123 & 0.21440 & 0.69564 & 0.38892 & 0.546242 & 17 \\
\hline 11 & 0.98147 & 0.58420 & 0.96426 & 0.54597 & 0.760521 & 4 \\
\hline 12 & 0.31406 & 0.18359 & 0.42161 & 0.37982 & 0.401254 & 22 \\
\hline 13 & 0.42639 & 0.40950 & 0.46572 & 0.45851 & 0.462206 & 21 \\
\hline 14 & 0.72191 & 0.15969 & 0.64260 & 0.37305 & 0.511306 & 19 \\
\hline 15 & 0.99418 & 0.55184 & 0.98849 & 0.52734 & 0.763871 & 3 \\
\hline 16 & 0.22128 & 0.23938 & 0.39102 & 0.39663 & 0.393752 & 23 \\
\hline 17 & 0.88978 & 0.32933 & 0.81937 & 0.42711 & 0.628308 & 10 \\
\hline 18 & 0.97409 & 0.49888 & 0.95073 & 0.49944 & 0.730916 & 5 \\
\hline 19 & 0.94791 & 0.56777 & 0.90565 & 0.53635 & 0.725770 & 6 \\
\hline 20 & 0.18102 & 0.09295 & 0.37908 & 0.35535 & 0.367523 & 24 \\
\hline 21 & 0.77599 & 0.49715 & 0.69060 & 0.49858 & 0.597070 & 12 \\
\hline 22 & 0.85483 & 0.30821 & 0.77499 & 0.41954 & 0.601857 & 11 \\
\hline 23 & 0 & 0 & 0.33333 & 0.33333 & 0.333333 & 25 \\
\hline 24 & 0.82830 & 0.24486 & 0.74438 & 0.39836 & 0.575840 & 15 \\
\hline 25 & 0.86078 & 0.66968 & 0.78220 & 0.60218 & 0.694517 & 7 \\
\hline
\end{tabular}

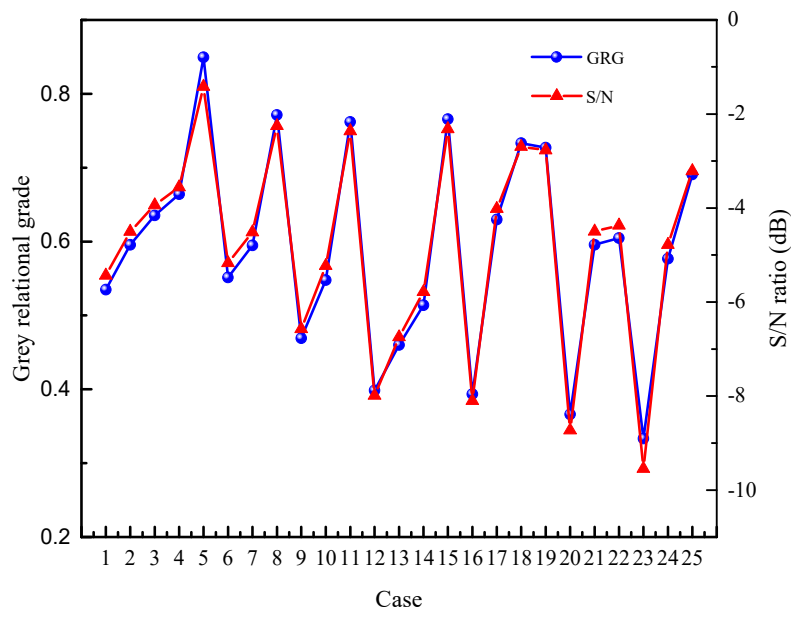

Figure 17. Grey relational grades presented in Table 12 and their $\mathrm{S} / \mathrm{N}$ (signal to noise) ratio. 
A response table was generated for the grey relational grade to describe the order of significance for each factor. As shown in Table 13, the order of importance of each factor was $D_{\mathrm{b}}>M_{\mathrm{a}}>T_{\text {g,in }}>M_{\mathrm{s}}>$ $H_{\mathrm{b}}$. Each factor and the levels resulting in the best and worst performance of multiple processes in the vertical cooling bed are shown in Figure 18. The diameter of the bed $\left(D_{\mathrm{b}}\right)$ was the most important factor, followed by the air mass flow rate $\left(M_{a}\right)$ in terms of the effect of the tested factors on the performance of multiple processes in the cooling bed, as shown in Figure 18.

Table 13. Factorial effects and weight factors for the grey relational grade.

\begin{tabular}{cccccc}
\hline Level & A & B & C & D & E \\
\hline 1 & -3.759 & -5.120 & -4.733 & -7.623 & -3.780 \\
2 & -4.747 & -5.082 & -4.874 & -5.872 & -3.855 \\
3 & -5.036 & -5.034 & -4.862 & -4.429 & -4.874 \\
4 & -5.267 & -4.687 & -5.001 & -3.519 & -5.708 \\
5 & -5.278 & -4.164 & -4.617 & -2.644 & -5.870 \\
Delta & 1.519 & 0.955 & 0.385 & 4.979 & 2.091 \\
Rank & 3 & 4 & 5 & 1 & 2 \\
\hline
\end{tabular}

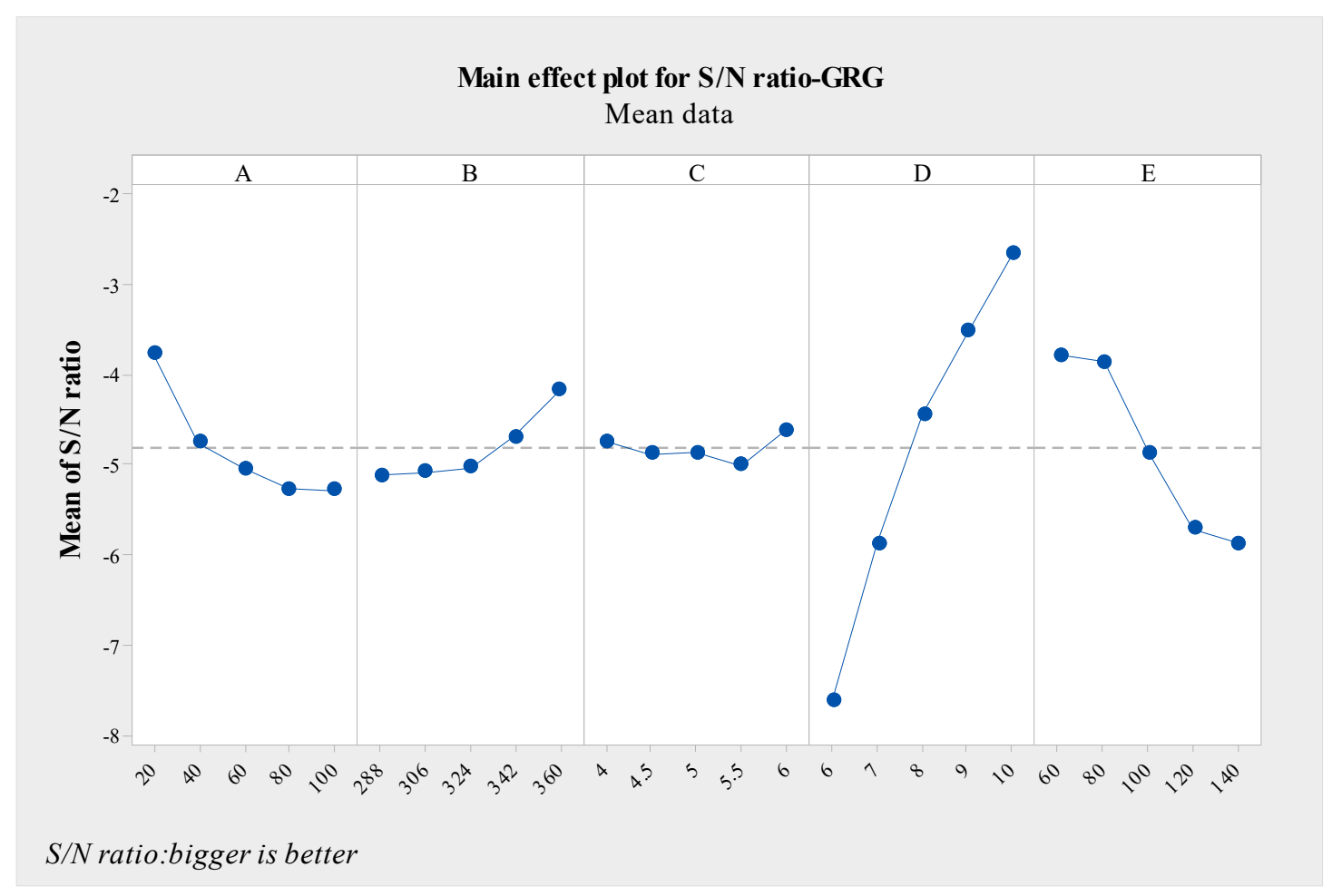

Figure 18. The effect of each factor on the performance of the two responses.

ANOVA was applied to reveal the contribution rates of the tested factors and verify the result of the response table for the grey relational grade. The results of the AVONA are shown in Table 14, and the diameter of the bed was the most important factor, followed by air mass flow rate and air inlet temperature for determining the performance of multiple processes. The height of the cooling bed and sinter mass flow exerted limited effects on multiple levels of performance of the cooling bed. The contributions of each factor to the grey relational grade are described in Figure 19. The results of the ANOVA were consistent with the response table (Table 13) for the grey relational grade. 
Table 14. ANOVA table for the grey relational grade.

\begin{tabular}{cccccc}
\hline Factors & D.O.F. & Sum of Squares & Variance & F-Value & Contribution (\%) \\
\hline A & 4 & 0.029458 & 0.007364 & 3.02 & 6.51 \\
B & 4 & 0.021308 & 0.005327 & 2.18 & 4.71 \\
C & 4 & 0.001212 & 0.000303 & 0.12 & 0.27 \\
D & 4 & 0.319099 & 0.079775 & 32.72 & 70.51 \\
E & 4 & 0.071697 & 0.017924 & 7.35 & 15.84 \\
Error & 4 & 0.009752 & 0.002438 & & 2.16 \\
Total & 24 & 0.452525 & & & 100.00 \\
\hline
\end{tabular}

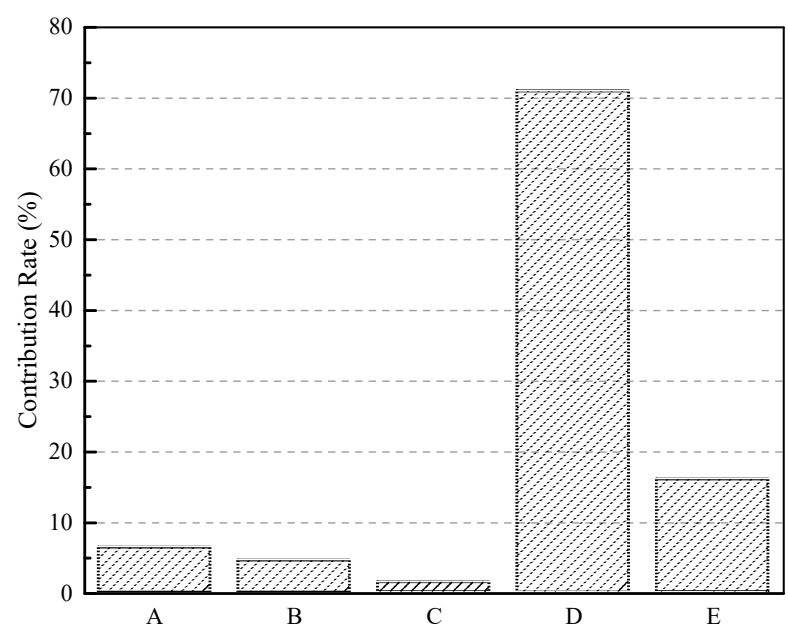

Figure 19. Contributions of each factor to the grey relational grade.

In addition, the regression analysis of the equation, including the design factors for GRG (grey relational grade), is expressed in Equation (36). The $\mathrm{R}^{2}$ value of $94.67 \%$ was obtained from the regression equation for the performance of multiple processes, and the standard deviation was 0.03687 .

$$
G R G=-0.179+(-0.001127) * A+0.001015 * B+0.0086 * C+0.08269 * D-0.001926 * E
$$

\subsubsection{Confirmation Test}

In this section, the confirmation test was an important step to verify the optimization of multiple responses. Table 15 shows a comparison of the effects of the optimal factor combination $\left(\mathrm{A}_{1} \mathrm{~B}_{5} \mathrm{C}_{5} \mathrm{D}_{5} \mathrm{E}_{1}\right)$ and initial factor combination $\left(\mathrm{A}_{1} \mathrm{~B}_{5} \mathrm{C}_{5} \mathrm{D}_{5} \mathrm{E}_{5}\right)$ for multiple performance characteristics. The confirmation experiment, including the optimal combination of design parameters, resulted in an exergy of outlet air and air pressure drop of $29.89 \mathrm{MJ} \cdot \mathrm{s}^{-1}$ and $2412.5 \mathrm{~Pa}$, respectively. The increases in the GRG value and corresponding percentage compared with the initial settings were 0.0727 and $8.51 \%$, respectively. Thus, the heat transfer and hydrodynamic performances of the sinter cooling process in the VSCB were improved with the aid of the Taguchi GRA method. In addition, the utilization of waste heat was increased, and energy loss was reduced. 
Table 15. Confirmation test for verification.

\begin{tabular}{cccc}
\hline Output & $\begin{array}{c}\text { Initial Parameter } \\
\text { Setting } \mathbf{A}_{\mathbf{1}} \mathbf{B}_{\mathbf{5}} \mathbf{C}_{\mathbf{5}} \mathbf{D}_{\mathbf{5}} \mathbf{E}_{\mathbf{5}}\end{array}$ & Prediction $\mathbf{A}_{\mathbf{1}} \mathbf{B}_{\mathbf{5}} \mathbf{C}_{\mathbf{5}} \mathbf{D}_{\mathbf{1}}$ & $\begin{array}{c}\text { Confirmation Experiment } \\
\mathbf{A}_{\mathbf{1}} \mathbf{B}_{\mathbf{5}} \mathbf{C}_{\mathbf{5}} \mathbf{D}_{\mathbf{5}} \mathbf{E}_{\mathbf{1}}\end{array}$ \\
\hline$E x\left(\mathrm{MJ} \cdot \mathrm{s}^{-1}\right)$ & 31.93 & & 29.89 \\
$P_{\text {drop }}(\mathrm{Pa})$ & 8328.9 & & 2412.5 \\
Grey relational grade $_{\text {GRA's S/N ratio (dB) }}{ }^{1}$ & 0.8541 & 0.9371 & 0.9268 \\
Improvement in GRG & -1.369 & -0.564 & -0.660 \\
\hline
\end{tabular}

${ }^{1}$ represent the grade relational analysis.

\section{Conclusions}

The CFD numerical simulation, coupled with the Taguchi-grey relational analysis method was applied in the present study to investigate the effects of geometric and operational factors on heat transfer and hydrodynamic performance. The exergy of air outlet recovery and the air pressure for the heat transfer process in the VSCB were selected as the response performance functions. The main conclusions are listed below.

The effect of design factors on the exergy of air outlet recovery was studied. The results revealed that the diameter and height of bed were the most important factors, with a contribution rate of $56.79 \%$ and $16.32 \%$, respectively. The optimal combination of factors for the exergy of air outlet recovery was $\mathrm{A}_{1} \mathrm{~B}_{5} \mathrm{C}_{5} \mathrm{D}_{5} \mathrm{E}_{2}$. In addition, the maximum exergy of recovery value was $29.68 \mathrm{MJ} \cdot \mathrm{s}^{-1}$, based on the optimal situation from the thermodynamics analysis.

The impact of design factors on air pressure was evaluated. The optimal condition was $\mathrm{A}_{1} \mathrm{~B}_{5} \mathrm{C}_{1} \mathrm{D}_{5} \mathrm{E}_{1}$, and the diameter of the bed and air mass flow rate were the most important factors affecting the hydrodynamic performance, with contribution rates of $57.08 \%$ and $29.22 \%$, respectively. Furthermore, the air pressure was simulated as $3703.8 \mathrm{~Pa}$, based on the combination of optimal factors from the hydrodynamics analysis.

The influence of geometric and structural factors on both of the maximum exergy of air outlet recovery and minimal air pressure drop was investigated. The optimal factor combination was $\mathrm{A}_{1} \mathrm{~B}_{5} \mathrm{C}_{5} \mathrm{D}_{5} \mathrm{E}_{1}$, while the diameter of the bed and air mass flow rate exerted the dominant effects on multiple performance measures, with contributions of $70.51 \%$ and $15.84 \%$, respectively. The optimum values for multiple performance characteristics based on the best combination were $29.89 \mathrm{MJ} \cdot \mathrm{s}^{-1}$ and 2412.5 Pa, respectively.

The confirmation test was performed to compare the optimum condition and initial condition based on the Taguchi with a grey relational analysis method to improve the heat transfer and hydrodynamic performances. The optimum results revealed increases in the GRG value and corresponding ratio by 0.0727 and $8.51 \%$, respectively, compared with the initial design.

Author Contributions: Conceptualization, J.F.; Methodology, J.F.; Experiments, J.F.; Software, J.F.; Resources, J.F.; Writing-Original Draft, J.F.; Writing-Review and Editing, J.F. and J.C.; Visualization, J.F. and J.C.; Supervision, J.F. and J.C.; Project Administration, J.F. and J.C. All authors have read and agreed to the published version of the manuscript.

Funding: This study was supported by the National Key R\&D Program of China (2017YFB0304200) and the National Science Foundation of China (51734004).

Conflicts of Interest: The authors have no conflict of interest to declare. 


\section{Nomenclature}

$\begin{array}{ll}\rho & \text { Air density }\left(\mathrm{kg} / \mathrm{m}^{3}\right) \\ \mathbf{u} & \text { Velocity vector }(-) \\ p & \text { Air pressure }(\mathrm{Pa}) \\ \mu & \text { Dynamic viscosity }(\mathrm{kg} / \mathrm{m} \cdot \mathrm{s}) \\ u & \text { Superficial velocity }(\mathrm{m} / \mathrm{s}) \\ k & \text { Turbulent kinetic energy }\left(\mathrm{m}^{2} / \mathrm{s}^{2}\right) \\ \varepsilon & \text { Turbulent energy dissipation rate }(1 / \mathrm{s}) \\ 1 / \alpha & \text { Coefficient of viscous resistance }(-) \\ C_{2} & \text { Coefficient of inertial resistance }(-) \\ \varphi & \text { Porosity }(-) \\ d_{p S M} & \text { Sauter mean diameter }(\mathrm{mm}) \\ c & \text { Specific heat }(\mathrm{J} /(\mathrm{kg} \cdot \mathrm{K})) \\ \lambda & \text { Thermal conductivity }(\mathrm{W} /(\mathrm{m} \cdot \mathrm{K})) \\ T & \text { Temperature }(\mathrm{K}) \\ h & \text { Area heat transfer coefficient }\left(\mathrm{W} /\left(\mathrm{m}^{2} \cdot \mathrm{K}\right)\right) \\ h_{v} & \text { Volume heat transfer coefficient }\left(\mathrm{W} /\left(\mathrm{m}^{3} \cdot \mathrm{K}\right)\right) \\ C F & \text { Correction factor }(-) \\ y_{i} & \text { Factor in the ith case }(-) \\ \mathrm{m} & \text { Total number of cases }(-) \\ S S_{\text {factor }} & \text { Total square of a single factor }(-) \\ N & \text { Number of levels of a factor }(-) \\ S S_{T} & \text { Sum of squares of factor }(-) \\ S S e & \text { Total square of error }(-) \\ S S_{A} & \text { Sum square of factor }(-) \\ f_{\text {factor }} & \text { Degree of freedom of factor }(-) \\ F_{f a c t o r} & \text { Variance ratio }(-) \\ V_{\text {factor }} & \text { Sum square of a single factor }(-) \\ V_{\text {error }} & \text { Sum error of a single factor }(-) \\ \text { Subscripts } & \\ f & \text { fluid } \\ s & \text { solid } \\ T & \text { error } \\ f a c t o r & \text { Parameter of interest } \\ & \end{array}$

\section{References}

1. Liu, Z.C.; Feng, Y.H.; Zhang, X.X.; Xu, L.; Yu, Z.D. Numerical and experimental study on coke size distribution in bell-type charging in the CDQ shaft. Int. J. Min. Met. Mater. 2008, 15, 236-240. [CrossRef]

2. Altohamy, A.A.; Elsemary, I.M.M.; Abdo, S.; Abodelrahman, M.A.; Attia, A.A.; Sakr, R.Y. Encapsulation surface roughness effect on the performance of cool storage systems. J. Energy Storage 2020, 28, 101279. [CrossRef]

3. Chiu, C.C.; Tsai, T.Y.; Tai, N.H.; Lee, C.Y. Synthesis of ultra long vertically aligned carbon nanotubes using the rapid heating and cooling system in the thermal chemical vapor deposition process. Surf. Coat. Technol. 2006, 200, 3215-3219. [CrossRef]

4. Ghafori, H. Computational fluid dynamics (CFD) analysis of pipeline in the food pellets cooling system. J. Stored Prod. Res. 2020, 87, 101581. [CrossRef]

5. Liu, Y.; Yang, J.; Wang, J.; Cheng, Z.L.; Wang, Q.W. Energy and exergy analysis for waste heat cascade utilization in sinter cooling bed. Energy 2014, 67, 370-380. [CrossRef]

6. Cai, J.J.; Dong, H. Method and Device of Sinter Waste Heat Recovery and Utilization with Vertical Tank. Chinese Patent 200910187381.8, 1 May 2011. (In Chinese) 
7. Liu, Y.; Yang, J.; Wang, J.Y.; Ding, X.G.; Cheng, Z.L.; Wang, Q.W. Prediction, parametric analysis and bi-objective optimization of waste heat utilization in sinter cooling bed using evolutionary algorithm. Energy 2015, 90, 24-35. [CrossRef]

8. Feng, H.; Chen, L.; Liu, X.; Xie, Z.; Sun, F. Constructural optimization of a sinter cooling process based on exergy output maximization. Appl. Therm. Eng. 2016, 96, 161-166. [CrossRef]

9. Feng, J.S.; Zhang, S.; Dong, H.; Pei, G. Effect of gas inlet parameters on exergy transfer performance of sinter cooling process in vertical moving bed. Appl. Therm. Eng. 2019, 152, 126-134. [CrossRef]

10. Zheng, Y.; Cai, J.J.; Dong, H.; Feng, J.S. Experimental investigation of volumetric exergy transfer coefficient in vertical moving bed for sinter waste heat recovery. Appl. Therm. Eng. 2019, 167, 428-439. [CrossRef]

11. Zheng, Y.; Dong, H.; Cai, J.J.; Feng, J.S.; Zhang, S. Experimental investigation of volumetric heat transfer coefficient in vertical moving-bed for sinter waste heat recovery. Appl. Therm. Eng. 2019, 151, 335-343. [CrossRef]

12. Pan, L.S.; Wei, X.Y.; Peng, Y.; Ma, Y.J.; Li, B. Theoretical study on the cooling procedure for vertical flow sinter. Appl. Therm. Eng. 2017, 127, 592-601. [CrossRef]

13. Feng, J.S.; Dong, H.; Gao, J.Y.; Liu, Y.J.; Liang, K. Experimental study of gas-solid overall heat transfer coefficient in vertical tank for sinter waste heat recovery. Appl. Therm. Eng. 2016, 95, 136-142. [CrossRef]

14. Zhang, S.; Zhao, L.; Feng, J.S.; Luo, X.F.; Dong, H. Thermal analysis of sinter vertical cooler based on waste heat recovery. Appl. Therm. Eng. 2019, 157, 113708. [CrossRef]

15. Feng, J.S.; Dong, H.; Gao, J.Y.; Li, H.Z.; Liu, Y.J. Numerical investigation of gas-solid heat transfer process in vertical tank for sinter waste heat recovery. Appl. Therm. Eng. 2016, 107, 135-143. [CrossRef]

16. Pan, L.S.; Wei, X.L.; Peng, Y.; Shi, X.B.; Liu, H.L. Experimental study on convection heat transfer and air drag in sinter layer. J. Cent. South. Univ. 2015, 22, 2841-2848. [CrossRef]

17. Feng, J.S.; Dong, H.; Dong, H.D. Modification of Ergun's correlation in vertical tank for sinter waste heat recovery. Powder Technol. 2015, 280, 89-93. [CrossRef]

18. Tian, F.Y.; Huang, L.F.; Fan, L.W. Pressure drop in a packed bed with sintered ore particles as applied to sinter coolers with a novel vertically arranged design for waste heat recovery. J. Zhejiang Univ.-Sci. A 2016, 17, 89-100. [CrossRef]

19. Prusty, J.K.; Pradhan, B. Multi-response optimization using Taguchi-Grey relational analysis for composition of fly ash-ground granulated blast furnace slag based geopolymer concrete. Constr. Build. Mater. 2020, 241, 118049. [CrossRef]

20. Liu, D.H.; Li, J.H.; Peng, Y.; Zhang, J.L.; Wang, G.W.; Xue, X. Comprehensive evaluation of sintering basic characteristics of iron ore based on grey relational analysis. J. Iron Steel Res. Int. 2019, 26, 691-696. [CrossRef]

21. Chamoli, S.; Yu, P.; Kumar, A. Multi-response optimization of geometric and flow parameters in a heat exchanger tube with perforated disk inserts by Taguchi grey relational analysis. Appl. Therm. Eng. 2016, 103, 1339-1350. [CrossRef]

22. Bademlioglu, A.H.; Canbolat, A.S.; Kaynakli, O. Multi-objective optimization of parameters affecting Organic Rankine Cycle performance characteristics with Taguchi-Grey Relational Analysis. Renew. Sustain. Energy Rev. 2020, 117, 109483. [CrossRef]

23. Canbolat, A.S.; Bademlioglu, A.H.; Arslanoglu, N.; Kaynali, P. Performance optimization of absorption refrigeration systems using Taguchi, ANOVA and Grey Relational Analysis method. J. Clean. Prod. 2019, 229, 874-885. [CrossRef]

24. Deepthi, Y.P.; Krishna, M.; Saramah, P. Optimization of electroless copper coating parameters on graphite particles using Taguchi and grey relational analysis. Mater. Today Proc. 2018, 5, 12077-12082. [CrossRef]

25. Erdinc, A.; Kelestemur, O. Optimization of mortars containing steel scale using Taguchi based grey relational analysis method. Constr. Build. Mater. 2019, 214, 232-241.

26. Nelabhotla, D.M.; Jayaraman, T.V.; Asghar, K.; Das, D. The optimization of chemical mechanical planarization process-parameters of c-plane gallium-nitride using Taguchi method and grey relational analysis. Mater. Des. 2016, 104, 392-403. [CrossRef]

27. Celik, N.; Pusat, G.; Turgut, E. Application of Taguchi method and grey relational analysis on a turbulated heat exchanger. Int. J. Therm. Sci. 2018, 124, 85-97. [CrossRef]

28. Kumbhar, D.G.; Sane, N.K. Numerical analysis and optimization of heat transfer and friction factor in dimpled tube assisted with regularly spaced twisted tapes using Taguchi and grey relational analysis. Proc. Eng. 2015, 127, 652-659. [CrossRef] 
29. Acir, A.; Canli, M.E.; Ata, I.; Cakiroglu, R. Parametric optimization of energy and exergy analyses of a novel solar air heater with grey relational analysis. Appl. Therm. Eng. 2017, 122, 330-338. [CrossRef]

30. Kuo, C.F.; Su, T.L.; Jhang, P.R.; Huang, C.Y.; Chiu, C.H. Using the Taguchi method and grey relational analysis to optimize the flat-plate collector process with multiple quality characteristics in solar energy collector manufacturing. Energy 2011, 36, 3554-3562.

31. Gunes, S.; Senyigit, E.; Karakaya, E.; Ozceyhan, V. Optimization of heat transfer and pressure drop in a tube with loose-fit perforated twisted tapes by Taguchi method and grey relational analysis. J. Therm. Anal. Calorim. 2019, 136, 1795-1806. [CrossRef]

32. Feng, J.S.; Zhang, S.; Dong, H.; Pei, G. Parameter study of sinter waste heat recovery in vertical tank based on energy and exergy analysis. J. Iron Steel Res. Int. 2020, 27, 22-32. [CrossRef]

33. Lau, C.S.; Abdullah, M.Z.; Ani, F.C. Optimization modeling of the cooling stage of reflow soldering process for ball grid array package using the grey-based Taguchi method. Microelectron. Reliab. 2012, 52, 1143-1152. [CrossRef]

34. Taguchi, G. Taguchi Techniques for Quality Engineering; McGraw-Hill: New York, NY, USA, 1988.

(C) 2020 by the authors. Licensee MDPI, Basel, Switzerland. This article is an open access article distributed under the terms and conditions of the Creative Commons Attribution (CC BY) license (http://creativecommons.org/licenses/by/4.0/). 